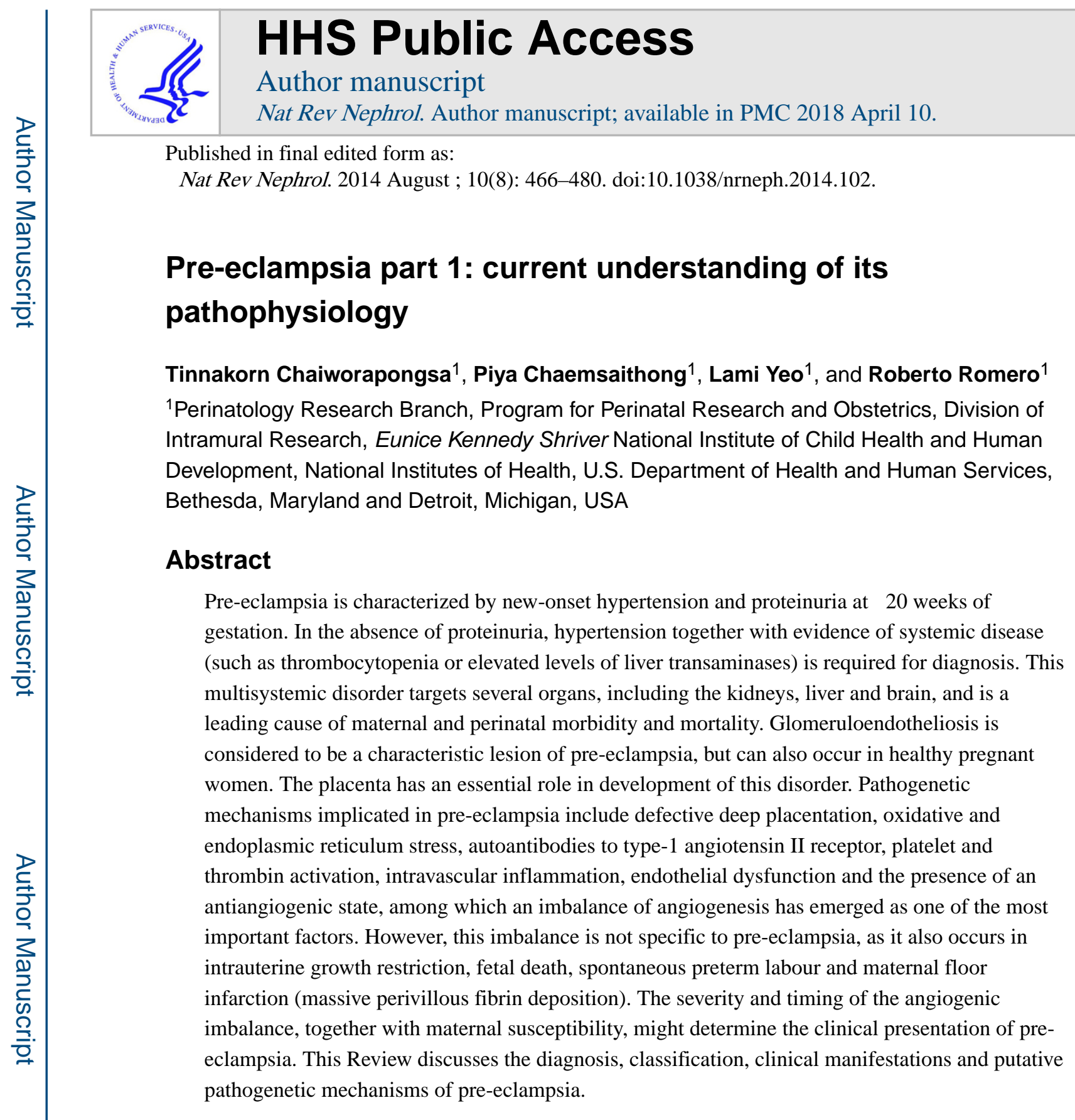

\title{
Introduction
}

Pre-eclampsia is characterized by new-onset hypertension and proteinuria at $\geq 20$ weeks of gestation. ${ }^{1-6}$ In the absence of proteinuria, diagnosis requires the presence of hypertension together with evidence of systemic disease (such as thrombocytopenia, elevated levels of liver transaminases, renal insufficiency, pulmonary oedema and visual or cerebral

Correspondence: Tinnakorn Chaiworapongsa MD, Perinatology Research Branch, NICHD/NIH/DHHS, Hutzel Women's Hospital / Wayne State University, 3990 John R, 4 Brush, Detroit, Michigan 48201, Telephone: (313) 993-2700, Fax: (313) 993-2694, tchaiwor@med.wayne.edu.

Disclosure: The authors report no conflicts of interest.

Author contributions

All authors researched data for the article, made substantial contributions to discussion of the content, wrote, reviewed and edited the manuscript before submission. 
disturbances). ${ }^{7,8}$ This gestation-specific syndrome affects $3-5 \%$ of all pregnancies, and is a leading cause of maternal and perinatal morbidity and mortality. ${ }^{1-7,9}$ Pre-eclampsia can progress to eclampsia, which is characterized by new-onset grand mal seizures and affects 2.7-8.2 women per 10,000 deliveries. ${ }^{10}$ Complications of pre-eclampsia or eclampsia include cerebrovascular accidents, liver rupture, pulmonary oedema or acute renal failure that can result in maternal death. ${ }^{11}$ Adverse perinatal outcomes of pre-eclampsia and eclampsia are attributed largely to preterm delivery, which occurs secondary to maternal or fetal complications, intrauterine growth restriction (IUGR) and fetal death. ${ }^{9}$

A placenta, but not the fetus, is required for the development of pre-eclampsia, as preeclampsia can occur in patients with hydatidiform moles. ${ }^{12}$ Indeed, the only effective treatment for pre-eclampsia is delivery of the placenta. The traditional view of the pathogenetic mechanisms involved in pre-eclampsia is that an ischaemic placenta produces soluble factors (formerly called toxins-hence the name toxaemia of pregnancy) that, when released into the maternal circulation, are responsible for the clinical manifestations of the disease. ${ }^{13,14}$ These soluble factors are thought to cause endothelial cell dysfunction, ${ }^{15,16}$ intravascular inflammation ${ }^{17-19}$ and activation of the haemostatic system; ${ }^{20}$ accordingly, pre-eclampsia is considered to be primarily a vascular disorder. The clinical manifestations of pre-eclampsia result from the involvement of multiple organs, including the kidneys, liver, brain, heart, lung, pancreas and the vasculature. ${ }^{2,21}$ This Review discusses the diagnosis, classification, clinical manifestations and putative pathogenetic mechanisms of preeclampsia. Its prediction, prevention and management will be addressed in part 2 of this Review as a separate article. ${ }^{22}$

\section{A historical overview}

Eclampsia was first recognized as a convulsive disorder of pregnancy; the name is derived from the Greek word eklampsis (meaning lightning), reflecting the sudden onset of convulsions in pregnant women. ${ }^{23}$ Albuminuria was reported in patients with eclampsia in $1840,{ }^{24}$ and approximately 50 years later, the presence of hypertension was also recognized in such patients. ${ }^{25}$ The term pre-eclampsia was subsequently introduced to describe the state preceding eclampsia. ${ }^{1}$ In the early 20th century, differentiating between glomerulonephritis (then known as Bright disease) and pre-eclampsia in pregnant women was challenging, as both conditions are associated with hypertension and proteinuria. ${ }^{21}$ The prevention of eclampsia was proposed as a major goal of prenatal care in 1901, which led directly to the current emphasis on detecting early signs of pre-eclampsia. ${ }^{26}$ As a consequence, pregnant women now have their blood pressure measured and urine tested for proteinuria at every antenatal visit.

\section{Risk factors}

Pre-eclampsia often occurs in young women having their first pregnancy. This observation has been attributed to an immune mechanism, as the maternal immune system develops tolerance to paternal alloantigens following exposure to seminal fluid and/or sperm. ${ }^{27}$ Prolonged exposure to semen is thought to decrease the risk of developing pre-eclampsia (Box 1), ${ }^{27}$ possibly explaining the increased risk of this condition in women with a short 
interval between first coitus and conception, those undergoing assisted reproductive technologies involving artificial insemination, women using barrier methods of contraception and in multiparous women who have changed partner since the previous pregnancy. ${ }^{27}$ A paternal component to the risk of pre-eclampsia has also been proposed, known as the 'dangerous father' hypothesis, according to which men who have fathered a previous pregnancy complicated by pre-eclampsia have an increased risk of doing so again with a new partner. ${ }^{28}$

Familial clustering supports a genetic component to the risk of developing pre-eclampsia. ${ }^{29}$ In twin studies, estimates of the heritability of pre-eclampsia range from $22 \%$ to $47 \% .^{30}$ Candidate-gene studies have demonstrated significant associations between DNA variants and pre-eclampsia for a few genes in the maternal and fetal genome, including collagen a1(I) chain (COL1A1), IL-1a (IL1A) for the maternal genotype and urokinase plasminogen activator surface receptor $(P L A U R)$ for the fetal genotype. ${ }^{31}$ Moreover, maternal-fetal genotype incompatibility of lymphotoxin-a ( $L T A)$, von Willebrand factor $(V W F)$ and collagen a2(IV) chain (COL4A2) seem to be a risk factor for pre-eclampsia. ${ }^{32}$ Other specific DNA variants that increase the risk of pre-eclampsia include the Factor V Leiden mutation, mutations in endothelial nitric oxide synthase, human leukocyte antigen and angiotensin-converting enzyme. ${ }^{33}$ A meta-analysis of 11 studies, involving 1,297 cases of pre-eclampsia and 1,791 controls, found a modest but significant association between preeclampsia and the single nucleotide polymorphism (SNP) rs1799889 in SERPINE1. Specifically, this association involved the $-6754 \mathrm{G} / 5 \mathrm{G}$ polymorphism ( $4 \mathrm{G}$ versus $5 \mathrm{G}$ ) and, for the recessive genetic model $(4 \mathrm{G} / 4 \mathrm{G}$ versus $4 \mathrm{G} / 5 \mathrm{G}+5 \mathrm{G} / 5 \mathrm{G})$, the odds ratio was 1.36 (95\% CI 1.13-1.64, $P=0.001) .{ }^{34}$ By contrast, a genome-wide association study of 177 cases of pre-eclampsia and 166 controls did not identify any variants associated with preeclampsia; ${ }^{35}$ however, associations with four SNPs in PSG11 (which encodes pregnancyspecific $\beta 1$-glycoprotein 11 ) reached nominal significance. ${ }^{35}$

\section{Diagnosis of pre-eclampsia}

\section{Typical presentation}

Pre-eclampsia is traditionally diagnosed by new-onset hypertension and proteinuria at $\geq 20$ weeks of gestation. Although hypertension is essential according to all diagnostic criteria, the requirement of proteinuria for the diagnosis of pre-eclampsia is a matter of debate. Some professional organizations allow diagnosis of pre-eclampsia on the basis of the presence of new-onset hypertension together with evidence of systemic involvement, such as thrombocytopenia, elevated levels of liver transaminases, renal insufficiency, pulmonary oedema and visual or cerebral disturbances (Box 2) ${ }^{7,8}$ The rationale for omitting proteinuria is that pre-eclampsia might manifest before glomerular capillary endotheliosis becomes severe enough to induce proteinuria. ${ }^{36,37}$ Moreover, patients with nonproteinuric preeclampsia (with evidence of systemic involvement) are more likely than those with gestational hypertension to have severe hypertension and undergo premature delivery. However, women with proteinuric pre-eclampsia are at greater risk than women with nonproteinuric pre-eclampsia to have severe hypertension, and deliver premature babies or babies who are small for their gestational age. ${ }^{38}$ 
The gold standard for diagnosis of proteinuria during pregnancy is total protein $\$ 300 \mathrm{mg}$ in a $24 \mathrm{~h}$ urine sample. However, this cut-off has not been adequately validated and might be too high; ${ }^{39}$ a subsequent study demonstrated that the mean total protein concentration in 24 $\mathrm{h}$ urine samples from normal pregnant women was $117.0 \mathrm{mg}$ (upper limit of 95\% CI -259.4 $\mathrm{mg}) .{ }^{39}$ Urinary dipstick tests for proteinuria are considered unreliable owing to variations in protein excretion, activity, diet and posture at the time of assessment. ${ }^{39}$ However, a dipstick result of $\geq 1+$ has a positive-predictive value of $82-92 \%$ for predicting $24 \mathrm{~h}$ urinary protein levels of $2300 \mathrm{mg} .{ }^{35,36} \mathrm{By}$ contrast, the negative predictive value of a negative or trace dipstick result was low (34-60\%). ${ }^{40,41}$ The assessment of proteinuria by protein:creatinine ratios is recommended in several guidelines, with the most commonly used cut-off value being $230 \mathrm{mg} / \mathrm{mmol}^{7}{ }^{7}$ However, protein:creatinine ratios can vary depending on the time of day the measurement is taken ${ }^{42}$ and this parameter might, therefore, be unreliable for the diagnosis of proteinuria. ${ }^{39}$ Indeed, a recent study examined the urinary protein:creatinine ratio at three different time points (at $0800 \mathrm{~h}, 1200 \mathrm{~h}$ and $1700 \mathrm{~h}$ ) and showed that the ratios varied throughout the day (mean coefficient of variation 36\%). However, no differences among the three measurements with respect to sensitivity (89-96\%) and specificity (75$78 \%$ ) to predict proteinuria were found. ${ }^{43}$ A systematic review concluded that the spot protein:creatinine ratio is a reasonable 'rule out' test for significant proteinuria during pregnancy because of its high sensitivity and low negative likelihood ratio $(0.12) .{ }^{44}$ Of note, although the presence of proteinuria can aid in the diagnosis of pre-eclampsia, the severity of proteinuria has limited prognostic value ${ }^{45}$ and, consequently, severe proteinuria has been removed from the diagnostic criteria for severe pre-eclampsia by some professional organizations. $^{7}$

\section{Atypical presentations}

Hypertension and proteinuria have been recognized as the essential criteria for diagnosis of pre-eclampsia. However, this multisystemic disease can also present with atypical manifestations, giving rise to its nickname 'the great imitator' ${ }^{46}$ Some patients present with HELLP syndrome (haemolysis, elevated liver transaminases, low platelets), ${ }^{47-49}$ which is widely regarded as a form of pre-eclampsia, despite it failing to meet conventional diagnostic criteria. HELLP syndrome occurs only in pregnant women, resolves with delivery and is frequently, but not always, associated with hypertension and proteinuria. ${ }^{50}$ Patients can also present with right upper quadrant pain (attributable to distention of the capsule of Glisson), and some components of HELLP syndrome, but without hypertension and proteinuria. ${ }^{50}$

\section{Classification}

Pre-eclampsia can be classified as early ( $<34$ weeks) or late ( $>34$ weeks), according to gestational age at diagnosis or delivery (Box 3). ${ }^{3,51}$ Although several other gestational age cut-offs have been suggested (such as 32 weeks and 36 weeks), ${ }^{52} 34$ weeks remains the most commonly used, ${ }^{53,54}$ presumably as the rate of neonatal morbidities declines considerably after reaching this gestational time point. For instance, in women with severe pre-eclampsia, expectant management is no longer considered and induction of labour is recommended after the 34th week of gestation. ${ }^{7}$ However, whether early and late pre-eclampsia have different pathogenetic mechanisms or are merely gradations of the same underlying 
condition remains unclear. ${ }^{55}$ Pre-eclampsia can also be classified according to its severity (Box 4); ${ }^{1,56}$ nonetheless, to avoid conveying a false sense of security to clinicians, some professional organizations have abandoned the term 'mild or severe' pre-eclampsia in favour of 'pre-eclampsia with or without severe features' 7

\section{Pathogenetic mechanisms}

\section{Placental ischaemia}

The central hypothesis governing our understanding of pre-eclampsia is that the disorder results from ischaemia of the placenta, which in turn releases factors into the maternal circulation that are capable of inducing the clinical manifestations of the disease. This concept emerged from observations that placental infarctions are common in patients with eclampsia. ${ }^{13}$ In 1914, researchers proposed that placental infarctions are due to interference with the maternal blood supply to the placenta, and that a necrotic placenta releases products directly into the intervillous space and maternal circulation. ${ }^{13}$ Importantly, this hypothesis was supported by studies in which the injection of placental extracts into guinea pigs elicited convulsions with hepatic and renal lesions, similar to those observed in women who died of eclampsia. ${ }^{13}$ In 1940, studies in pregnant dogs showed that clamping of the abdominal aorta (which reduced uteroplacental perfusion by 50\%) led to maternal hypertension that resolved after release of the clamp (Figure 1). This hypertensive response was not observed in nonpregnant dogs. ${ }^{57} \mathrm{~A}$ uteroplacental origin of the signal driving this hypertensive response was supported by the observation that, after removal of the pregnant uterus, clamping of the aorta no longer elicited hypertension. ${ }^{57}$ Subsequent work revealed that uteroplacental blood flow is decreased in women with pre-eclampsia. ${ }^{58}$

\section{Transformation of the spiral arteries}

During a normal pregnancy, uterine blood flow increases to enable perfusion of the intervillous space of the placenta and to support fetal growth. The increased blood flow is achieved by physiological transformation of the spiral arteries of the uterus, a process in which trophoblasts invade the arterial wall, destroy the media and transform the spiral arteries from narrow-diameter to large-diameter vessels, thereby enabling adequate perfusion of the placenta (Figures 2 and 3a). ${ }^{59}$

In pre-eclampsia (and eclampsia), the myometrial segment of the spiral artery fails to undergo physiological transformation during the second trimester (Figures 2 and $3 \mathrm{~b}$ ), ${ }^{60}$ which is thought to explain the uteroplacental ischaemia observed in pre-eclampsia. Moreover, nontransformed spiral arteries are prone to atherosis, characterized by the presence of lipid-laden macrophages within the lumen, fibrinoid necrosis of the arterial wall and a mononuclear perivascular infiltrate. ${ }^{61,62}$ The atherotic lesions resemble atherosclerotic plaques and are proposed to result from several pathophysiological mechanisms that include immunological reaction against fetal tissue, ${ }^{63,64}$ shear flow stress caused by abnormal blood flow in nontransformed spiral arteries, a systemic inflammatory response that involves the uterine decidua and maternal genetic predisposition. ${ }^{65}$ Atherosis might further impede blood flow to the placenta during the third trimester. However, the reader should note that failure of physiological transformation of the spiral arteries is neither specific to pre-eclampsia nor 
sufficient to cause it, ${ }^{66}$ as such failure has also been observed in other obstetric syndromes, including spontaneous abortion, ${ }^{67,68}$ IUGR, ${ }^{69,70}$ fetal death, ${ }^{68}$ placental abruption, ${ }^{71}$ preterm labour ${ }^{72}$ and preterm premature rupture of membranes. ${ }^{73}$ The mechanisms responsible for failure of physiological transformation of the spiral arteries have not been fully elucidated.

Human pregnancy is characterized by deep placentation, in which trophoblast cells in the placental bed invade not only the decidua, but also one-third of the thickness of the myometrium. $59,66,74$ As invasive trophoblasts are responsible for transformation of the spiral arteries, some researchers have suggested that an abnormality in trophoblasts might result in shallow placentation and inadequate transformation of the spiral arteries, leading to preeclampsia. $^{75}$

Other than trophoblast abnormalities, the effects of shear stress on vascular endothelium can affect remodelling of the spiral arteries. The diameter of the uterine artery (especially the proximal portion of vessels that are upstream of the branches into the spiral arteries) increases prior to completion of placentation, possibly as a consequence of the vasodilatatory properties of elevated levels of oestrogen. ${ }^{76}$ Blood flow in the uterine arteries also changes during the first few weeks of pregnancy and subsequently, haemochorial placentation converts the spiral arteries into a low-velocity, high-flow chamber. ${ }^{59}$ Decreased downstream resistance accelerates blood flow velocity in afferent (radial and arcuate) arteries, increasing shear stress on the arterial wall. The increase in shear stress stimulates the endothelium to augment its production of nitric oxide, resulting in vasodilatation, which further lowers uterine vascular resistance, and in turn, normalizes shear stress on the arterial wall. The increase in blood flow resulting from a large lumen (but decreased flow velocity) might stimulate changes in both vascular smooth muscle and the extracellular matrix and, in turn, vascular remodelling. ${ }^{77}$

\section{Hypoxia and trophoblast invasion}

Upon arrival of the conceptus to the endometrium, nutrition is initially provided by secretions from the endometrial glands (histiotrophic nutrition). ${ }^{78}$ Subsequently, the blastocyst invades the decidua. In the early phases of implantation, the gestational sac exists in an environment with low oxygen tension, which favours trophoblast proliferation. Trophoblasts anchor the blastocyst to maternal tissues, and also plug the tips of the spiral arteries within the decidua. ${ }^{79}$ Eventually, lacunae are formed within the trophoblasts, which subsequently coalesce to create the intervillous space. Opening of the spiral arteries into the intervillous space enables the development of haemochorial placentation, and shifts nutrition from a histiotrophic to haematotrophic type. ${ }^{80}$

The initial burst of blood into the intervillous space increases oxygen tension, generating oxidative stress on the trophoblasts, which promotes trophoblast differentiation from a proliferative to an invasive phenotype. Differentiated trophoblasts invade deeper into the decidua, reaching into the superficial myometrium ${ }^{80}$ and facilitating physiological transformation of the spiral arteries. Thus, the initial phase of placentation occurs under conditions of relative hypoxia. ${ }^{81}$ Indeed, hypoxia-inducible factor (HIF)-1a, a marker of cellular oxygen deprivation, is expressed at high levels in trophoblasts. Persistent hypoxia or failure to downregulate transforming growth factor $\beta 3$ (TGF- $\beta 3$ ) expression after 9 weeks of 
gestation might result in failure of trophoblasts to differentiate from the proliferative to invasive phenotype ${ }^{82}$ shallow trophoblast invasion and inadequate transformation of the spiral arteries, ${ }^{82}$ although this hypothesis remains unproven.

Considerable evidence supports a role for hypoxia in creating an environment that predisposes to implantation disorders, including pre-eclampsia: expression of HIF-1a and HIF- $2 a$ protein is increased in the placentas of women with pre-eclampsia; ${ }^{83}$ overexpression of HIF-1a leads to hypertension, proteinuria and fetal growth restriction in mice; ${ }^{84}$ mice with deletion of the Comt gene, which encodes catechol $O$-methyltransferase (an enzyme that catabolizes estradiol to 2-methoxyestradiol), develop hypertension and proteinuria when pregnant; ${ }^{85}$ and 2-methoxyestradiol, an inhibitor of HIF-1a, can suppress the production of soluble vascular endothelial growth factor receptor 1 (sVEGFR-1), a potent antiangiogenic factor. ${ }^{85}$ This observation is consistent with the finding that women with pre-eclampsia had lower placental COMT protein expression ${ }^{85}$ and serum levels of 2-methoxyestradiol ${ }^{85}$ than healthy controls; however, these findings could not be replicated in subsequent studies. ${ }^{86,87}$ An important point to note is that direct evidence for the presence of hypoxia in the intervillous space in patients destined to develop pre-eclampsia is lacking because these measurements cannot be performed in ongoing pregnancies. Moreover, expression of HIF-1a is upregulated not only by hypoxia, but also by inflammatory stimuli (for example, thrombin, vasoactive peptides, cytokines, such as tumour necrosis factor [TNF], and reactive oxygen species $[\mathrm{ROS}])$, especially those mediated by nuclear factor $\kappa \mathrm{B}(\mathrm{NF}-\mathrm{\kappa B})$, as the promoter of HIF-1a contains an NF- $\mathrm{kB}$ binding site. ${ }^{88}$

Inadequate deep placentation can also result from a decidual defect; optimal decidualization requires proper preconditioning, which is achieved by successive menstruations. ${ }^{89}$ Inadequate preconditioning might explain the high rate of pre-eclampsia in young women (such as those aged $<20$ years). ${ }^{89}$ Another possibility is that defective placentation might be the result of combinations of factors that affect both decidua and trophoblasts. ${ }^{89}$ Indeed, implantation creates conditions in which fetal cells (carrying paternal antigens) and maternal cells come into contact in the decidua; a role for the immune system in normal placentation is, therefore, easy to envision. Successful pregnancy requires that the maternal immune system does not reject the trophoblast. ${ }^{27}$ Roles for natural killer cells in the decidua, HLA-C molecules on the fetal trophoblast (its only known polymorphic histocompatibility antigen) and regulatory $\mathrm{T}$ cells have been implicated in the tolerogenic state associated with normal pregnancy, as well as in pre-eclampsia. ${ }^{27}$

Maternal-fetal immune recognition at the site of placentation is highly individualized by two polymorphic gene systems: HLA-C molecules of trophoblasts and their cognate receptors, killer cell immunoglobulin-like receptors (KIRs) of natural killer cells. ${ }^{27}$ At least two haplotype groups of KIR (A and B) and two types of HLA-C (C1 and C2) are known. HLA$\mathrm{C} 2$ interacts with KIRs more strongly than does HLA-C1. ${ }^{27,90}$ Uterine natural killer cells release chemokines, angiogenic factors and cytokines that promote trophoblast invasion. These secretions are increased upon binding of HLA-C antigens to stimulatory KIRs (haplotype B), whereas they are reduced by antigen binding to haplotype A of KIRs. Thus, KIR BB mothers carrying HLA-C1 fetuses might have the best chance of adequate 
placentation and avoiding pre-eclampsia. By contrast, KIR AA mothers carrying HLA-C2

fetuses might have an increased susceptibility to pre-eclampsia. ${ }^{27,90}$

\section{Endoplasmic reticulum stress}

Narrow spiral arteries create conditions for ischaemia-reperfusion injury in the intervillous space. This injury, in turn, might lead to endoplasmic reticulum (ER) stress, which regulates cell homeostasis through its involvement in post-translational modifications and protein folding. ${ }^{91}$ During states of energy crisis (such as hypoxia), the ER suspends protein folding (referred to as the unfolded protein response, or UPR). ${ }^{92}$ The UPR can lead to cessation of cell proliferation and, when severe, apoptosis. Trophoblast apoptosis ${ }^{93}$ results in the release of microparticles and nanoparticles into the maternal circulation, which can stimulate an intravascular inflammatory response. ${ }^{94}$ Evidence supporting the involvement of ER stress in pre-eclampsia and IUGR includes activation of the UPR, as shown by upregulation of factors involved in several signalling pathways characteristic of UPR activation following ER stress in the placenta. ${ }^{92,95}$

\section{Oxidative stress}

Oxidative stress arises when the production of ROS overwhelms the intrinsic antioxidant defence mechanisms operating in tissues. ${ }^{96}$ Oxidative stress is relevant to the pathophysiology of pre-eclampsia, as it induces the release of proinflammatory cytokines and chemokines as well as trophoblast debris. ${ }^{97}$ The cause of oxidative stress in the placentas of women with pre-eclampsia is thought to be intermittent hypoxia and reoxygenation, probably resulting from deficient conversion of the myometrial segment of the spiral arteries, which contains a contractile portion of the artery. ${ }^{96}$ Indeed, radiographic studies of the spiral arteries note these constricted portions at the myometrial segment of the spiral artery just proximal to the myometrial-endometrial junction in both the human and the rhesus monkey. ${ }^{98,99}$

Increased ROS exposure can lead to protein carboxylation, lipid peroxidation and DNA oxidation - all of which have been observed in placentas of patients with pre-eclampsia. ${ }^{96}$ Under pathological conditions, such as hypoxia or ischaemia-reperfusion injury, increased conversion of xanthine dehydrogenase to xanthine oxidase promotes the production of uric acid and superoxide from degraded purines (such as xanthine and hypoxanthine). ${ }^{96}$ Xanthine oxidase expression and activity are increased in invasive trophoblasts obtained from patients with pre-eclampsia. ${ }^{100}$ Furthermore, placental antioxidant mechanisms are impaired in patients with pre-eclampsia, as shown by their decreased expression of superoxide dismutase and glutathione peroxidase compared with women with normal pregnancies. ${ }^{101}$

Another important source of free radicals in humans is free haeme, a pro-oxidant molecule produced daily via the degradation of circulating red blood cells. Protection from free haeme is afforded by the actions of haeme oxygenase, which converts free haeme first to biliverdin and subsequently to bilirubin, releasing free iron and carbon monoxide. ${ }^{102}$ Biliverdin and bilirubin have potent antioxidant properties, whereas carbon monoxide induces vasodilatation, has antiapoptotic properties and promotes angiogenesis. ${ }^{102}$ Three isoforms of haeme oxygenase have been characterized: HO-1 (inducible), HO-2 (constitutive) and HO-3 
(unknown function). ${ }^{102}$ Several lines of evidence support a role for haeme oxygenases in the pathogenesis of pre-eclampsia. Pregnant $\mathrm{Hmox}_{\mathrm{I}^{+/}}$mice, which have a partial deficiency in HO-1, demonstrate hypertension, small placentas and elevated plasma levels of sVEGFR-1 (all features of pre-eclampsia). ${ }^{103} \mathrm{HO}-1$ and HO-2 mRNA $^{104}$ and protein ${ }^{105}$ expression are decreased in women with pre-eclampsia (the decreased protein expression was detected in peri-infarct regions of the placenta). ${ }^{105}$ In trophoblasts obtained from women at 11 weeks gestation, HO-1 mRNA expression was lower in individuals who went on to develop preeclampsia than in those who had a normal pregnancy. ${ }^{106}$ mRNA expression of superoxide dismutase and catalase are also lower in peripheral blood samples from patients with preeclampsia than in samples from normal pregnant women. ${ }^{104}$ These findings indicate that pre-eclampsia is associated with a deficiency of antioxidant enzymes in the placenta and probably in the peripheral blood as well. ${ }^{104}$ Interest in manipulating the expression of HO-1 as a potential therapeutic intervention for pre-eclampsia has been fuelled by preclinical studies; pharmacological induction of HO-1 expression (by cobalt protoporphyrin or pravastatin) can attenuate hypertension, decrease oxidative stress and reduce serum concentrations of sVEGFR-1 in rodent models of pre-eclampsia (generated by either reduced uterine perfusion pressure ${ }^{107}$ or overexpression of sVEGFR-1 resulting from adenovirus-mediated sFIt1 gene transfer). ${ }^{108}$

\section{Antibodies to type-1 angiotensin II receptor}

Normal pregnancy is characterized by reduced vascular responsiveness to angiotensin II. ${ }^{109}$ However, pregnant women with pre-eclampsia have increased sensitivity to the effects of angiotensin II, a difference that can be detected as early as 24 weeks of gestation. ${ }^{109}$ The mechanisms responsible for the physiological refractoriness to angiotensin II in normal pregnancy and the enhanced response to it in pre-eclampsia include genetic predisposition, maladaptive immune responses and environmental triggers. ${ }^{110}$ A subset of women with preeclampsia have detectable serum autoantibodies against type- 1 angiotensin II receptor $\left(\mathrm{AT}_{1}\right)$, 111 and such autoantibodies can activate $\mathrm{AT}_{1}$ in endothelial cells, vascular smooth muscle cells and mesangial cells. In pregnant rats, anti- $\mathrm{AT}_{1}$ autoantibodies (either produced endogenously in response to transgenic expression of human renin and angiotensinogen ${ }^{112}$ or administered by injection of purified anti- $\mathrm{AT}_{1}$ autoantibodies from women with preeclampsia ${ }^{113}$ ) leads to hypertension, proteinuria, glomerular capillary endotheliosis and increased production of sVEGFR-1 ${ }^{114}$ and soluble endoglin ${ }^{114}$ - these effects can be attenuated by administration of losartan (an $\mathrm{AT}_{1}$-receptor blocker). These observations indicate that proteinuria and renal pathology in rats with anti- $\mathrm{AT}_{1}$ autoantibodies might result from $\mathrm{AT}_{1}$ activation. Anti-AT 1 autoantibodies can stimulate the synthesis of NADPH oxidase, a rate-limiting enzyme in the synthesis of ROS, leading to oxidative stress. ${ }^{115}$ These autoantibodies can also stimulate tissue factor release by monocytes and vascular smooth muscle cells, as well as plasminogen activator inhibitor-1 (PAI-1) release by mesangial and trophoblast cells. ${ }^{115}$ Collectively, these actions can lead to increased thrombin generation, impaired fibrinolysis and consequently fibrin deposition. Anti- $\mathrm{AT}_{1^{-}}$ autoantibodies can also stimulate placental production of sVEGFR-1 and, therefore, lead to an antiangiogenic state. ${ }^{114}$ 
Of interest, reduced uterine perfusion pressure in rats induces production of anti- $\mathrm{AT}_{1^{-}}$ autoantibodies, sVEGFR-1, TNF and endothelin-1, as well as hypertension and proteinuria. ${ }^{116}$ Similarly, administration of TNF, ${ }^{116}$ IL-6 ${ }^{116}$ or IL-17 117 to pregnant rats results in hypertension, placental oxidative stress and enhanced $\mathrm{AT}_{1}$ activity, the effects of which can be abrogated by $\mathrm{AT}_{1}$ blockade. Furthermore, anti- $\mathrm{AT}_{1}$ autoantibodies stimulate deposition of complement $\mathrm{C} 3$ in the placenta and kidneys of pregnant mice, whereas treatment with a complement $\mathrm{C} 3 \mathrm{a}$ receptor antagonist inhibited autoantibody-induced elevation of sVEGFR-1, small placenta formation and IUGR. ${ }^{118}$ These findings suggest that anti-AT 1 autoantibodies mediate hypertension during pregnancy through activation of complement C3 and production of antiangiogenic factors. ${ }^{118}$ However, it is noteworthy that glomerular capillary endotheliosis, a characteristic renal lesion of pre-eclampsia, has not been demonstrated in the reduced uterine perfusion pressure rat model of pre-eclampsia. ${ }^{116}$

A subset of B cells $\left(\mathrm{CD} 19^{+} \mathrm{CD}^{+}\right)$might be involved in production of anti- $\mathrm{AT}_{1}$ autoantibodies in pre-eclampsia, as addition of sera from patients with pre-eclampsia to these cells increased both the proportion of $\mathrm{CD} 19^{+} \mathrm{CD}^{+}$cells and anti- $\mathrm{AT}_{1}$ autoantibody activity. ${ }^{119}$ Moreover, the proportion of $\mathrm{CD} 19^{+} \mathrm{CD}^{+} \mathrm{B}$ cells was also enriched in peripheral blood from patients with pre-eclampsia versus that from women with normal pregnancies. By contrast, administration of rituximab (an antibody directed against CD20, a costimulatory molecule on $\mathrm{B}$ cells) to rats with reduced uterine perfusion pressure reduced anti- $\mathrm{AT}_{1}$ autoantibody titres, blood pressure and endothelin-1 levels, as well as depleting $\mathrm{B}$ cells. Adoptive transfer of $\mathrm{CD}^{+} \mathrm{T}$ lymphocytes from rats with reduced uterine perfusion pressure to normal pregnant rats increased blood pressure and anti-AT1 autoantibody activity. ${ }^{119}$ These effects were abrogated by administration of losartan or by B-cell depletion using rituximab. ${ }^{120}$

Some investigators have proposed that parvovirus infection might be a predisposing factor for pre-eclampsia, as the $\mathrm{AT}_{1}$ epitope recognized by anti- $\mathrm{AT}_{1}$ autoantibodies shares a high degree of homology with parvovirus B19 capsid proteins. ${ }^{121}$ However, the presence of parvovirus B19 IgG (a marker of previous viral infection) does not correlate with the presence or activity of anti-AT 1 autoantibodies. ${ }^{122}$ Currently, the lack of an immunoassay for this specific $\mathrm{AT}_{1}$ epitope might hinder progress in the understanding and implementation of anti-AT 1 autoantibody testing in clinical practice.

\section{Intravascular inflammation}

Normal pregnancy is characterized by phenotypic and functional evidence of activation of circulating granulocytes and monocytes, ${ }^{17,123}$ and the magnitude of this intravascular inflammatory response is increased in patients with pre-eclampsia. ${ }^{17-19}$ Observational evidence supporting this view includes findings of elevated levels of proinflammatory cytokines in maternal blood of pre-eclampsia. ${ }^{124}$ Experimental studies have also shown that some features of pre-eclampsia, such as hypertension and placental oxidative stress, can be elicited by administration of TNF, ${ }^{125}$ IL-6 ${ }^{125}$ or IL-17. ${ }^{117}$ Although the maternal manifestations of pre-eclampsia have been attributed to intravascular inflammation, ${ }^{17-19}$ several studies have demonstrated that patients with other obstetric syndromes (such as preterm labour with intact membranes, ${ }^{126}$ preterm prelabour rupture of membranes, ${ }^{127}$ 
IUGR $^{128,129}$ and pyelonephritis ${ }^{123}$ ) have evidence of intravascular inflammation without hypertension and proteinuria. Intravascular inflammation is, therefore, a feature of preeclampsia, but is not sufficient to cause the disorder. The mechanisms responsible for intravascular inflammation in pre-eclampsia are thought to include increased release of microparticles and nanoparticles from the syncytiotrophoblast into the maternal circulation, 94 as well as proinflammatory cytokines and chemokines released upon activation of NF- $\kappa B$ in the context of ER and oxidative stress. ${ }^{97}$

\section{Endothelial cell activation and/or dysfunction}

Endothelial cell activation and/or dysfunction has been proposed to be a central feature of pre-eclampsia ${ }^{130}$ _a concept that has considerable appeal, as vasospasm is a key component of this disorder. Proteinuria can also be considered as a manifestation of damage to the fenestrated glomerular endothelium. In the original observation supporting this hypothesis, sera from patients with pre-eclampsia (but not from normal pregnant women) induced the release of ${ }^{51} \mathrm{Cr}$ by human umbilical vein endothelial cells. ${ }^{16,130}$ Subsequent studies showed that maternal levels of E-selectin and vascular cell adhesion protein 1 (VCAM-1) were higher in patients with pre-eclampsia than in normal pregnant women. ${ }^{131}$ However, the Eselectin findings are not specific for pre-eclampsia, as elevated levels are also observed in other obstetric syndromes (including pregnancies with small for gestational age fetuses). ${ }^{132}$ Endothelial cell activation and/or dysfunction is postulated to be secondary to intravascular inflammation. ${ }^{18}$ Given that other obstetric syndromes also feature intravascular inflammation, a clear explanation of why this phenomenon would lead to endothelial cell dysfunction in some patients and not others is lacking. One possibility is that the different clinical presentations depend upon the degree of inflammation and/or maternal susceptibility to endothelial cell injury.

\section{Platelet and thrombin activation}

Pre-eclampsia can be associated with thrombocytopenia (owing to platelet consumption), which is also associated with adverse pregnancy outcomes. ${ }^{49}$ Moreover, thrombocytopenia can occur before the development of hypertension. ${ }^{49}$ Several lines of evidence support a role of platelet activation in pre-eclampsia: increased platelet size, reduced platelet lifespan, increased maternal plasma levels of platelet factor $4, \beta$-thromboglobulin and platelet-specific proteins stored in a granules (and released upon activation) and increased production of thromboxane B2 by platelets. ${ }^{20}$ Platelet activation might also lead to thrombi in the microcirculation of several target organs. ${ }^{2}$

Since vasospasm and platelet consumption are features of pre-eclampsia, this disorder was proposed to represent an endothelium-platelet abnormality owing to a deficiency in prostacyclin. ${ }^{2}$ Indeed, prostacyclin has vasodilatatory effects and inhibits platelet aggregation. ${ }^{2}$ Reduced levels of a stable metabolite of prostacyclin in maternal blood ${ }^{133}$ and $u_{\text {urine }}^{2}$ has been reported in association with pre-eclampsia. Moreover, the placentas of women with pre-eclampsia produce more thromboxane A2 than prostacyclin, and thromboxane A2 can induce vasoconstriction and platelet aggregation. ${ }^{134}$ A similar argument has been made for a role of nitric oxide in pre-eclampsia, as a deficiency of nitric oxide can cause vasoconstriction and increased platelet aggregation. ${ }^{135}$ Experimental 
evidence supporting this hypothesis came from the observation that administration of nitric oxide blockers (inhibitors of nitric oxide synthase such as or L-nitroarginine methyl ester) to pregnant rats resulted in a pre-eclampsia-like syndrome that included hypertension, proteinuria, IUGR and glomerular injury. ${ }^{136}$

A prominent feature of pre-eclampsia is activation of soluble components of the coagulation cascade. ${ }^{137}$ Excessive thrombin generation has been consistently demonstrated in preeclampsia ${ }^{138}$ and can be subclinical in nature, or lead to overt disseminated intravascular coagulation in the presence of placental abruption. Excessive thrombin generation might be related to endothelial cell dysfunction, platelet activation, chemotaxis of monocytes, proliferation of lymphocytes, neutrophil activation or excessive generation of tissue factor in response to the activity of proinflammatory cytokines, such as IL- $1 \beta$ and TNF. Thrombin activation can also lead to deposition of fibrin in multiple organ systems, which is a major contributor to the pathology of pre-eclampsia. ${ }^{2}$ Excessive thrombin generation can be assessed by measuring the concentration of thrombin-antithrombin complexes, ${ }^{138}$ antithrombin III activity ${ }^{139}$ or by a thrombin generation assay. ${ }^{140}$ In some patients, preeclampsia and/or HELLP syndrome can be considered as thrombotic microangiopathy-like disorders, in light of the similarities in clinical presentation and pathology observed in multiple organs (thrombocytopenia, haemolysis, endothelial injury, complement activation and deposition of thrombin and/or fibrin in arterioles and capillaries of the brain, kidneys and liver). Examples of other thrombotic microangiopathic disorders include thrombotic thrombocytopenic purpura and haemolytic uremic syndrome. ${ }^{141}$

\section{An antiangiogenic state}

Angiogenesis, the formation of new blood vessels from pre-existing ones, is essential for a successful pregnancy. ${ }^{142}$ Defective angiogenesis has long been considered as a pathway to pre-eclampsia, ${ }^{143}$ and rigorous research showed that an antiangiogenic state is involved in the pathogenesis of pre-eclampsia. ${ }^{144}$ Following on from observations that patients with cancer who were treated with antiangiogenic agents—-such as bevacizumab, which targets vascular endothelial growth factor (VEGF)-A—developed proteinuria and hypertension, ${ }^{145}$ an analysis of differential gene expression patterns (microarray experiments) showed that mRNA levels of the soluble VEGF receptor VEGFR-1 were higher in the placentas of patients with pre-eclampsia than in those of healthy pregnant women. ${ }^{144}$ Subsequently, persuasive evidence was gathered in support of the concept that sVEGFR-1 has a role in the pathogenesis of pre-eclampsia: the median plasma and/or serum levels of sVEGFR-1 are higher in women with pre-eclampsia than in women with normal pregnancies; ${ }^{144,146,147}$ preeclampsia is associated with decreased plasma and/or serum levels of free VEGF and placental growth factor (PIGF); ${ }^{143,144}$ sera from women with pre-eclampsia demonstrated antiangiogenic effects on endothelial tube formation (a bioassay for angiogenesis), and this effect could be reversed by addition of VEGF and PIGF; ${ }^{144}$ high levels of sVEGFR-1 in pregnant animals (achieved by adenovirus-mediated sFIt1 gene transfer) induced hypertension, proteinuria and glomerular capillary endotheliosis; ${ }^{144}$ maternal plasma concentrations of sVEGFR-1 are increased prior to clinical diagnosis of preeclampsia ${ }^{146,148-150}$ and decrease dramatically after delivery; ${ }^{144}$ maternal plasma levels of sVEGFR-1 are higher in severe pre-eclampsia than in forms of the disease without severe 
features (previously termed mild pre-eclampsia), as well as higher in early than in late preeclampsia; ${ }^{146,147}$ levels of sVEGFR-1 in plasma samples from the uterine vein are significantly higher than in samples from the antecubital vein in patients with pre-eclampsia, but not in normal pregnant women; ${ }^{151}$ and several risk factors for pre-eclampsia are associated with increased plasma and/or serum levels of sVEGFR-1 (including a history of pre-eclampsia, ${ }^{152}$ nulliparity, ${ }^{153}$ multi-fetal gestations, ${ }^{154}$ diabetes mellitus, ${ }^{155}$ chronic hypertension ${ }^{152}$ and gestational hypertension ${ }^{156}$ ).

The primary source of the elevated plasma levels of sVEGFR-1 in pre-eclampsia is the placenta, ${ }^{144}$ although sVEGFR-1 can also be produced by peripheral blood mononuclear cells, macrophages, endothelial cells and vascular smooth muscle cells. ${ }^{157}$ Initially, sVEGFR-1 was reported to be a $\sim 90 \mathrm{kDa}$ protein that also existed in a glycosylated form, with a molecular weight ranging 100-120 kDa. Subsequent studies found several variants of this protein, including 60, 100, 145 and $185 \mathrm{kDa}$ isoforms. The $100 \mathrm{kDa}$ isoform (and, to a lesser extent, the $145 \mathrm{kDa}$ isoform) was the main isoform found in cultured cytotrophoblasts, peripheral blood mononuclear cells and uterine microvascular cells, whereas the $145 \mathrm{kDa}$ (along with the $100 \mathrm{kDa}$ ) isoform was the predominant form in the plasma of women with pre-eclampsia in one study. ${ }^{158}$ Another study found that the $130 \mathrm{kDa}$ sVEGFR $1_{-14}$ variant (which is expressed specifically in vascular smooth muscle cells) is the predominant isoform in the placenta and serum of women with pre-eclampsia. ${ }^{159}$ Reduced uteroplacental blood flow, ${ }^{160,161}$ damage to the villous trees, ${ }^{162}$ syncytial shedding of antiangiogenic factors, ${ }^{162}$ oxidative stress, ${ }^{103}$ anti-AT 1 autoantibodies, ${ }^{113}$ proinflammatory cytokines, ${ }^{114}$ excess thrombin ${ }^{163}$ and hypoxia ${ }^{164}$ have all been proposed to be responsible for the shift in the balance of angiogenic and antiangiogenic factors in favour of an antiangiogenic state in preeclampsia (Figure 4).

\section{sVEGFR-1 induced hypertension and proteinuria}

sVEGFR-1 exerts antiangiogenic effects by binding to and inhibiting the biological activity of circulating VEGF and PIGF. ${ }^{165}$ VEGF is important for the maintenance of endothelial cell function, especially in fenestrated endothelium, which is found in brain, liver and glomeruli. ${ }^{166}$ Indeed, knockout of even only a single allele ( $\mathrm{Vegfa}^{+/-}$) results in progressive endothelial degeneration, which is fatal at days $11-12$ in mice. ${ }^{142}$ Increased availability of sVEGFR-1 in pre-eclampsia might also counteract the nitric-oxide-induced vasodilatatory effects of VEGF, which result in hypertension. ${ }^{144}$ Indeed, plasma nitrite and sVEGFR-1 levels are inversely correlated in pre-eclampsia. ${ }^{167}$ The overall effect of increased production of sVEGFR-1 is increased maternal vascular tone, which maintains uterine perfusion. Moreover, sVEGFR-1 might antagonize the effects of VEGF-A, and thereby prime endothelial cells to have increased sensitivity to proinflammatory factors such as TNF. These findings suggest the possibility of convergent effects between an antiangiogenic factor and a proinflammatory cytokine. 168

In addition, sVEGFR-1 can induce proteinuria by blocking the effects of VEGF-A. Mice with podocyte-specific deletion of Vegfa develop glomerular capillary endotheliosis, the renal lesion observed in pre-eclampsia. ${ }^{169}$ Conversely, overexpression of VEGF-A in podocytes leads to end-stage renal disease, indicating that appropriate expression of VEGF- 
$\mathrm{A}$ is essential for maintenance of glomerular function. ${ }^{169}$ Furthermore, women in the second trimester (25-28 weeks gestation) who subsequently developed pre-eclampsia, and those at the time of diagnosis of pre-eclampsia, have higher numbers of podocytes per milligram of creatinine in their urine, identified by immunostaining for podocin after culturing urinary sediments for $24 \mathrm{~h}$, than do those with a normal pregnancy. ${ }^{170}$ In another study, the number of urinary podocytes (identified by immunostaining for podocalyxin) per millilitre of urine correlated with total urinary protein, systolic and diastolic blood pressure, and was inversely correlated with both free PIGF and the PIGF to sVEGFR-1 ratio at the time of diagnosis of pre-eclampsia. ${ }^{170,171}$ These observations strengthen the evidence supporting an imbalance between angiogenic and antiangiogenic factors and podocyte injury as having a role in development of the clinical features of pre-eclampsia.

\section{Role of soluble endoglin}

Pregnant rats with sVEGFR-1 overexpression (owing to adenovirus-mediated transfection with $s F l t 1$ ) do not display the full spectrum of clinical symptoms observed in pre-eclampsia. 172 Specifically, these animals develop hypertension, proteinuria and glomerular capillary endotheliosis, but not fetal growth restriction, liver dysfunction or thrombocytopenia. ${ }^{172} \mathrm{~A}$ second antiangiogenic factor implicated in the pathogenesis of preeclampsia is soluble endoglin, a cell-surface co-receptor of TGF- $\beta 1$ and TGF- $\beta 3$ that induces migration and proliferation of endothelial cells. ${ }^{172}$ Loss-of-function mutations in the human $E N G$ gene cause hereditary haemorrhagic telangiectasia, a disease characterized by vascular malformations. ${ }^{173}$ Mice lacking endoglin $\left(\mathrm{Eng}^{-/-}\right)$die from defective vascular development, poor vascular smooth muscle development and arrest of endothelial remodelling. ${ }^{174}$

Recombinant soluble endoglin inhibits endothelial tube formation to the same extent as does sVEGFR-1 in in vitro assays. ${ }^{172}$ Combined administration of adenoviral vectors encoding endoglin and $s$ FIt- 1 to pregnant rats generated a phenotype resembling HELLP syndrome. ${ }^{172}$ Evidence for the involvement of soluble endoglin in the pathogenetic mechanisms of preeclampsia includes higher maternal plasma concentrations of soluble endoglin in women with pre-eclampsia than in healthy pregnant women, both before ${ }^{156}$ and at the time of 172 clinical diagnosis; levels correlated with severity of disease. ${ }^{156,172}$ Furthermore, higher maternal serum levels of soluble endoglin were recorded in patients with HELLP syndrome than in those with pre-eclampsia but without HELLP syndrome. ${ }^{172}$ However, subsequent studies found that plasma levels of soluble endoglin in patients with HELLP syndrome were either higher than ${ }^{175}$ or not significantly different from ${ }^{176}$ those in patients with preeclampsia, indicating that soluble endoglin might not be a specific marker for HELLP syndrome.

\section{Specificity of the angiogenic balance}

Abnormalities in the profiles of angiogenic and antiangiogenic factors are not pathognomonic for pre-eclampsia. Indeed, such abnormalities are also present in other conditions, including IUGR, ${ }^{150,177}$ spontaneous preterm labour, ${ }^{178}$ fetal death, ${ }^{179,180}$ maternal floor infarction (massive perivillous fibrin deposition), ${ }^{181}$ spontaneous abortion ${ }^{182}$ and placental abruption with hypertension. ${ }^{183}$ Precisely why abnormal angiogenic and antiangiogenic profiles are associated with pre-eclampsia as well as these other complications of pregnancy remains to be elucidated. We believe that the severity and timing 
of the antiangiogenic state, and probably also maternal susceptibility, might determine the phenotype. For example, a profoundly antiangiogenic state could lead to fetal death, with lesser degrees of severity resulting in pre-eclampsia with IUGR, isolated IUGR or preterm labour with intact membranes. Moreover, several obstetric conditions that are considered to be risk factors for pre-eclampsia-such as molar pregnancy, ${ }^{184}$ pregnancies with fetal trisomy 13 (the FLT1 gene, which encodes VEGFR-1, is located on chromosome 13) ${ }^{185}$ and twin-to-twin transfusion syndrome ${ }^{186}$ _also have disruption in the balance of angiogenic and antiangiogenic factors, either in the placenta or peripheral blood.

\section{'Great obstetrical syndromes'}

Obstetric disorders, in contrast to diseases in the nonpregnant state, develop in the context of a unique biological situation-two individuals with different genomes coexisting, one inside the other. The common interest of mother and fetus is successful reproduction; however, conflict can occur when the interests of mother and fetus diverge, perhaps as the result of insults (such as infection or a compromised blood supply). We have proposed the term 'great obstetrical syndromes' to describe common features of important obstetric diseases. These features include multiple aetiologies, a long subclinical phase, fetal involvement, generally adaptive clinical manifestations and the involvement of gene-environment interactions. 187,188 Although this concept emerged in the context of preterm labour, it applies equally to pre-eclampsia. For example, it has become increasingly clear that pre-eclampsia is not one disorder, but rather different entities recognized by a common phenotype (hypertension and proteinuria), which represents the manifestation of one or more insults to the uteroplacental unit. Thus, we should not be surprised that multiple pathogenetic mechanisms and predisposing factors have been implicated in pre-eclampsia. Patients at risk of pre-eclampsia have an abnormal response to angiotensin II weeks before the clinical diagnosis can be made, ${ }^{109}$ and abnormal uterine artery Doppler velocimetry measurements and elevated levels of angiogenic factors often manifest months before a clinical diagnosis of preeclampsia. Within this long subclinical phase lies the opportunity for prediction and prevention of pre-eclampsia. Although pre-eclampsia is diagnosed by clinical signs in the mother (hypertension and proteinuria), fetal involvement can manifest as IUGR as well as other more-subtle abnormalities, such as thrombocytopenia or neutropenia. ${ }^{189}$ Importantly, hypertension is not the cause of pre-eclampsia, but it can be considered an adaptive response of the ischaemic uteroplacental unit, which signals to the mother the need to maintain perfusion. The resolution of maternal hypertension that follows fetal death in some patients with pre-eclampsia supports this view. ${ }^{190}$ However, adaptive responses can become maladaptive; for instance, a hypertensive crisis can result in cerebrovascular accident and maternal death. Finally, the factors that determine pre-eclampsia are likely to result from a combination of genetic predisposition and environmental factors. Patients with urinary tract infections or asymptomatic bacteriuria (considered to result from environmental exposure) during pregnancy are at increased risk of developing pre-eclampsia. ${ }^{191}$ Familial clustering of cases $^{29}$ and the results of candidate gene studies suggest that pre-eclampsia has a genetic component ${ }^{33}$ however, a gene-environment interaction for pre-eclampsia remains to be proven. Pre-eclampsia also shares many features with atherosclerosis, in which solid evidence of gene-environment interactions exists. An attractive possibility is that pre- 
eclampsia could be considered a pregnancy-specific clinical manifestation of an increased risk of atherosclerosis. ${ }^{65}$ This concept might explain why mothers with pre-eclampsia are at increased risk of cardiovascular disease later in life. Pre-eclampsia can also be considered to have survival value. A compromised uterine blood supply can lead to IUGR, which is an adaptive mechanism whereby the fetus slows its growth to avoid outstripping the delivery of oxygen. This adaptation alone might be sufficient for the fetus to reach the end of pregnancy. However, when IUGR alone is insufficient, signals originating from an ischaemic placenta increase the maternal blood pressure to sustain the fetus and prevent its death.

\section{Conclusions}

Pre-eclampsia is a leading cause of maternal and perinatal morbidity and mortality. The diagnosis of pre-eclampsia is currently based on nonspecific clinical symptoms and laboratory tests. Multiple pathogenetic mechanisms have been implicated in this disorder, among which an imbalance between angiogenic and antiangiogenic factors has emerged as one of the most important. Thus, diagnosis and subclassification of pre-eclampsia based on biomarkers of specific aetiologies might be useful for identifying patients at risk, monitoring disease progression and providing effective interventions. The roles of anti-AT 1 autoantibodies, B cells and gene-environment interactions in the pathogenesis of preeclampsia and other obstetric syndromes should be investigated. Further understanding of the mechanisms of abnormal placentation could advance current knowledge of the pathogenesis of pre-eclampsia as well as other disorders, such as fetal growth restriction, stillbirth and some types of spontaneous preterm delivery. In part 2 of this Review, we discuss the prediction, prevention and management of pre-eclampsia. ${ }^{22}$

\section{Review criteria}

A search for original research and review articles published in English between 1840 and 2013 focusing on pre-eclampsia was performed in PubMed, using the following search terms, alone or in combination: "pre-eclampsia," "toxaemia," "pregnancy-induced hypertension" and "eclampsia." The bibliographies of pertinent articles were also examined to identify further relevant papers.

\section{Acknowledgments}

\section{Funding}

The authors' research is supported, in part, by the Perinatology Research Branch, Division of Intramural Research, Eunice Kennedy Shriver National Institute of Child Health and Human Development, NIH, Department of Health and Human Services (NICHD/NIH/DHHS) and, in part, with Federal funding from the NICHD and NIH under contract no. HHSN275201300006C.

\section{References}

1. Lindheimer, MD., Roberts, JM., Cunningham, GC., Chesley, L. Chesley's Hypertensive Disorders in Pregnancy. Lindheimer, MD.Roberts, JM., Cunningham, GC., editors. Elsevier; 2009. p. 1-24.

2. Romero R, Lockwood C, Oyarzun E, Hobbins JC. Toxemia: new concepts in an old disease. Semin. Perinatol. 1988; 12:302-323. [PubMed: 3065943] 
3. Redman CW, Sargent IL. Latest advances in understanding preeclampsia. Science. 2005; 308:15921594. [PubMed: 15947178]

4. Roberts JM, Gammill HS. Preeclampsia: recent insights. Hypertension. 2005; 46:1243-1249. [PubMed: 16230510]

5. Sibai B, Dekker G, Kupferminc M. Pre-eclampsia. Lancet. 2005; 365:785-799. [PubMed: 15733721]

6. Steegers EA, von Dadelszen P, Duvekot JJ, Pijnenborg R. Pre-eclampsia. Lancet. 2010; 376:631644. [PubMed: 20598363]

7. American College of Obstetricians and Gynecologists Task Force on Hypertension in Pregnancy, Hypertension in Pregnancy [online]. 2013. http://www.acog.org/resources_and_publications/ task_force_and_work_group_reports/hypertension_in_pregnancy

8. Lowe SA, et al. Guidelines for the management of hypertensive disorders of pregnancy 2008. Aust. NZ J. Obstet. Gynaecol. 2009; 49:242-246.

9. Hutcheon JA, Lisonkova S, Joseph KS. Epidemiology of pre-eclampsia and the other hypertensive disorders of pregnancy. Best Pract. Res. Clin. Obstet. Gynaecol. 2011; 25:391-403. [PubMed: 21333604]

10. Thornton C, Dahlen H, Korda A, Hennessy A. The incidence of preeclampsia and eclampsia and associated maternal mortality in Australia from population-linked datasets: 2000-2008. Am. J. Obstet. Gynecol. 2013; 208:476. e471-e475. [PubMed: 23467048]

11. Adu-Bonsaffoh K, Samuel OA, Binlinla G. Maternal deaths attributable to hypertensive disorders in a tertiary hospital in Ghana. Int. J. Gynaecol Obstet. 2013; 123:110-113. [PubMed: 23969337]

12. Acosta-Sison H. The relationship of hydatidiform mole to pre-eclampsia and eclampsia; a study of 85 cases. Am. J. Obstet. Gynecol. 1956; 71:1279-1282. [PubMed: 13313644]

13. Young J. The aetiology of eclampsia and albuminuria and their relation to accidental haemorrhage: (an anatomical and experimental investigation.). Proc. R. Soc. Med. 1914; 7:307-348.

14. Page EW. On the pathogenesis of pre-eclampsia and eclampsia. J. Obstet. Gynaecol Br. Commonw. 1972; 79:883-894. [PubMed: 4563794]

15. Rodgers GM, Taylor RN, Roberts JM. Preeclampsia is associated with a serum factor cytotoxic to human endothelial cells. Am. J. Obstet. Gynecol. 1988; 159:908-914. [PubMed: 3177546]

16. Roberts JM, Edep ME, Goldfien A, Taylor RN. Sera from preeclamptic women specifically activate human umbilical vein endothelial cells in vitro: morphological and biochemical evidence. Am. J. Reprod. Immunol. 1992; 27:101-108. [PubMed: 1418401]

17. Sacks GP, Studena K, Sargent K, Redman CW. Normal pregnancy and preeclampsia both produce inflammatory changes in peripheral blood leukocytes akin to those of sepsis. Am. J. Obstet. Gynecol. 1998; 179:80-86. [PubMed: 9704769]

18. Redman CW, Sacks GP, Sargent IL. Preeclampsia: an excessive maternal inflammatory response to pregnancy. Am. J. Obstet. Gynecol. 1999; 180:499-506. [PubMed: 9988826]

19. Gervasi MT, et al. Phenotypic and metabolic characteristics of monocytes and granulocytes in preeclampsia. Am. J. Obstet. Gynecol. 2001; 185:792-797. [PubMed: 11641653]

20. Kenny, LC., Baker, PN., Cunningham, FG. Chesley's Hypertensive Disorders in Pregnancy. Lindheimer, MD.Roberts, JM., Cunningham, GC., editors. Elsevier; 2009. p. 335-351.

21. Lindheimer, MD., Roberts, JM., Cunningham, GC., Chesley, L. Chesley's Hypertensive Disorders in Pregnancy. Lindheimer, MD.Roberts, JM., Cunningham, GC., editors. Elsevier; 2009. p. 25-36.

22. Chaiworapongsa, T., Chaemsaithong, P., Korzeniewski, SJ., Yeo, L., Romero, R. Pre-eclampsia part 2: prediction, prevention and management. Nat. Rev. Nephrol. http://dx.doi.org/10.1038/ nrneph.2014.103

23. Lindheimer MDW. Benson and Pamela Harer Seminar on History. The History of Preeclampsia and Eclampsia as Seen by a Nephrologist. 2012

24. Lever JC. Cases of puerperal convulsions with remarks. Guys Hosp. Rep. 1843; 2:495-517.

25. Ballantyne JW. Sphygmographic tracings in puerperal eclampsia. Edinburgh Med. J. 1885; 30:1007-1020.

26. Ballantyne JW. A plea for a pro-maternity hospital. Br. Med. J. 1901; 1:813-814. [PubMed: 20759529] 
27. Redman CW, Sargent IL. Immunology of pre-eclampsia. Am. J. Reprod. Immunol. 2010; 63:534543. [PubMed: 20331588]

28. Dekker G, Robillard PY, Roberts C. The etiology of preeclampsia: the role of the father. J. Reprod. Immunol. 2011; 89:126-132. [PubMed: 21529966]

29. Chesley LC, Annitto JE, Cosgrove RA. The familial factor in toxemia of pregnancy. Obstet. Gynecol. 1968; 32:303-311. [PubMed: 5742111]

30. Thornton JG, Macdonald AM. Twin mothers, pregnancy hypertension and pre-eclampsia. Br. J. Obstet. Gynaecol. 1999; 106:570-575. [PubMed: 10426615]

31. Goddard KA, et al. Candidate-gene association study of mothers with pre-eclampsia, and their infants, analyzing 775 SNPs in 190 genes. Hum. Hered. 2007; 63:1-16. [PubMed: 17179726]

32. Parimi N, et al. Analytical approaches to detect maternal/fetal genotype incompatibilities that increase risk of pre-eclampsia. BMC Med. Genet. 2008; 9:60. [PubMed: 18598365]

33. Ward, K., Lindheimer, MD. Chesley's Hypertensive Disorders in Pregnancy. Lindheimer, MD.Roberts, JM., Cunningham, GC., editors. Elsevier; 2009. p. 51-71.

34. Zhao L, Bracken MB, Dewan AT, Chen S. Association between the SERPINE1 (PAI-1) 4G/5G insertion/deletion promoter polymorphism (rs1799889) and pre-eclampsia: a systematic review and meta-analysis. Mol. Hum. Reprod. 2013; 19:136-143. [PubMed: 23180602]

35. Zhao L, et al. Genome-wide association study identifies a maternal copy-number deletion in PSG11 enriched among preeclampsia patients. BMC Pregnancy Childbirth. 2012; 12:61. [PubMed: 22748001]

36. Morgan MA, Thurnau GR. Pregnancy-induced hypertension without proteinuria: is it true preeclampsia? South. Med. J. 1988; 81:210-213. [PubMed: 3340875]

37. Barton JR, O'Brien JM, Bergauer NK, Jacques DL, Sibai BM. Mild gestational hypertension remote from term: progression and outcome. Am. J. Obstet. Gynecol. 2001; 184:979-983. [PubMed: 11303208]

38. Homer CS, Brown MA, Mangos G, Davis GK. Non-proteinuric pre-eclampsia: a novel risk indicator in women with gestational hypertension. J. Hypertens. 2008; 26:295-302. [PubMed: 18192844]

39. Lindheimer MD, Kanter D. Interpreting abnormal proteinuria in pregnancy: the need for a more pathophysiological approach. Obstet. Gynecol. 2010; 115:365-375. [PubMed: 20093912]

40. Meyer NL, Mercer BM, Friedman SA, Sibai BM. Urinary dipstick protein: a poor predictor of absent or severe proteinuria. Am. J. Obstet. Gynecol. 1994; 170:137-141. [PubMed: 8296815]

41. Kuo VS, Koumantakis G, Gallery ED. Proteinuria and its assessment in normal and hypertensive pregnancy. Am. J. Obstet. Gynecol. 1992; 167:723-728. [PubMed: 1530030]

42. Lindow SW, Davey DA. The variability of urinary protein and creatinine excretion in patients with gestational proteinuric hypertension. Br. J. Obstet. Gynaecol. 1992; 99:869-872. [PubMed: 1450132]

43. Verdonk, K., et al. Variation of urinary protein to creatinine ratio during the day in women with suspected pre-eclampsia. BJOG. http://dx.doi.org/10.1111/1471-0528.12803

44. Cote AM, et al. Diagnostic accuracy of urinary spot protein:creatinine ratio for proteinuria in hypertensive pregnant women: systematic review. BMJ. 2008; 336:1003-1006. [PubMed: 18403498]

45. Thangaratinam $\mathrm{S}$, et al. Estimation of proteinuria as a predictor of complications of pre-eclampsia: a systematic review. BMC Med. 2009; 7:10. [PubMed: 19317889]

46. Goodlin RC. Severe pre-eclampsia: another great imitator. Am. J. Obstet. Gynecol. 1976; 125:747753. [PubMed: 945695]

47. Weinstein L. Syndrome of hemolysis, elevated liver enzymes, and low platelet count: a severe consequence of hypertension in pregnancy. Am. J. Obstet. Gynecol. 1982; 142:159-167. [PubMed: 7055180]

48. Romero R, et al. Clinical significance of liver dysfunction in pregnancy-induced hypertension. Am. J. Perinatol. 1988; 5:146-151. [PubMed: 3348861]

49. Romero R, et al. Clinical significance, prevalence, and natural history of thrombocytopenia in pregnancy-induced hypertension. Am. J. Perinatol. 1989; 6:32-38. [PubMed: 2783368] 
50. Sibai BM. Diagnosis, controversies, and management of the syndrome of hemolysis, elevated liver enzymes, and low platelet count. Obstet. Gynecol. 2004; 103:981-991. [PubMed: 15121574]

51. von Dadelszen P, Magee LA, Roberts JM. Subclassification of preeclampsia. Hypertens. Pregnancy. 2003; 22:143-148. [PubMed: 12908998]

52. Crispi F, et al. Predictive value of angiogenic factors and uterine artery Doppler for early-versus late-onset pre-eclampsia and intrauterine growth restriction. Ultrasound Obstet. Gynecol. 2008; 31:303-309. [PubMed: 18058842]

53. Soto E, et al. Late-onset preeclampsia is associated with an imbalance of angiogenic and antiangiogenic factors in patients with and without placental lesions consistent with maternal underperfusion. J. Matern. Fetal Neonatal Med. 2012; 25:498-507. [PubMed: 21867402]

54. Parra-Cordero M, et al. Prediction of early and late pre-eclampsia from maternal characteristics, uterine artery Doppler and markers of vasculogenesis during first trimester of pregnancy. Ultrasound Obstet. Gynecol. 2013; 41:538-544. [PubMed: 22807133]

55. Ogge $\mathrm{G}$, et al. Placental lesions associated with maternal underperfusion are more frequent in early-onset than in late-onset preeclampsia. J. Perinat. Med. 2011; 39:641-652. [PubMed: 21848483]

56. Sibai BM. Evaluation and management of severe preeclampsia before 34 weeks' gestation. Am. J. Obstet. Gynecol. 2011; 205:191-198. [PubMed: 22071049]

57. Ogden E, Hildebrand GJ, Page EW. Rise of blood pressure during ischemia of gravid uterus. Proc. Soc. Exp. Bio Med. 1940; 43:49-51.

58. Lunell NO, Nylund LE, Lewander R, Sarby B. Uteroplacental blood flow in pre-eclampsia measurements with indium-113m and a computer-linked gamma camera. Clin. Exp. Hypertens. B. 1982; 1:105-117. [PubMed: 7184662]

59. Brosens I, Robertson WB, Dixon HG. The physiological response of the vessels of the placental bed to normal pregnancy. J. Pathol. Bacteriol. 1967; 93:569-579. [PubMed: 6054057]

60. Brosens I, Renaer M. On the pathogenesis of placental infarcts in pre-eclampsia. J. Obstet. Gynaecol Br. Commonw. 1972; 79:794-799. [PubMed: 4651288]

61. Hertig AT. Vascular pathology in hypertensive albuminuric toxemias of pregnancy. Clinics. 1945; 4:1011-1015.

62. De Wolf F, Robertson WB, Brosens I. The ultrastructure of acute atherosis in hypertensive pregnancy. Am. J. Obstet. Gynecol. 1975; 123:164-174. [PubMed: 1163579]

63. Robertson WB, Brosens I, Dixon HG. The pathological resonse of the vessels of the placental bed to hypertensive pregnancy. J. Pathol. Bacteriol. 1967; 93:581-592. [PubMed: 6054058]

64. Labarrere CA. Acute atherosis. A histopathological hallmark of immune aggression? Placenta. 1988; 9:95-108. [PubMed: 3283724]

65. Staff AC, Dechend R, Redman CW. Review: Preeclampsia, acute atherosis of the spiral arteries and future cardiovascular disease: two new hypotheses. Placenta. 2013; 34(Suppl):S73-S78. [PubMed: 23246096]

66. Brosens I, Pijnenborg R, Vercruysse L, Romero R. The "Great Obstetrical Syndromes" are associated with disorders of deep placentation. Am. J. Obstet. Gynecol. 2011; 204:193-201. [PubMed: 21094932]

67. Khong TY, Liddell HS, Robertson WB. Defective haemochorial placentation as a cause of miscarriage: a preliminary study. Br. J. Obstet. Gynaecol. 1987; 94:649-655. [PubMed: 3620413]

68. Ball E, Bulmer JN, Ayis S, Lyall F, Robson SC. Late sporadic miscarriage is associated with abnormalities in spiral artery transformation and trophoblast invasion. J. Pathol. 2006; 208:535542. [PubMed: 16402350]

69. Brosens IA, Robertson WB, Dixon HG. The role of the spiral arteries in the pathogenesis of preeclampsia. Obstet. Gynecol. Annu. 1972; 1:177-191. [PubMed: 4669123]

70. Khong TY, De Wolf F, Robertson WB, Brosens I. Inadequate maternal vascular response to placentation in pregnancies complicated by pre-eclampsia and by small-for-gestational age infants. Br. J. Obstet. Gynaecol. 1986; 93:1049-1059. [PubMed: 3790464]

71. Dommisse J, Tiltman AJ. Placental bed biopsies in placental abruption. Br. J. Obstet. Gynaecol. 1992; 99:651-654. [PubMed: 1390469] 
72. Kim YM, et al. Failure of physiologic transformation of the spiral arteries in patients with preterm labor and intact membranes. Am. J. Obstet. Gynecol. 2003; 189:1063-1069. [PubMed: 14586356]

73. Kim YM, et al. Failure of physiologic transformation of the spiral arteries in the placental bed in preterm premature rupture of membranes. Am. J. Obstet. Gynecol. 2002; 187:1137-1142. [PubMed: 12439491]

74. Pijnenborg, R., Brosens, I. Placental Bed Disorders: Basic Science and its Translation to Obstetrics. Pijnenborg, R.Brosens, I., Romero, R., editors. Cambridge University Press; 2010. p. 97-108.

75. Zhou Y, Damsky CH, Fisher SJ. Preeclampsia is associated with failure of human cytotrophoblasts to mimic a vascular adhesion phenotype. One cause of defective endovascular invasion in this syndrome? J. Clin. Invest. 1997; 99:2152-2164. [PubMed: 9151787]

76. Rosenfeld CR, Roy T, Cox BE. Mechanisms modulating estrogen-induced uterine vasodilation. Vascul. Pharmacol. 2002; 38:115-125. [PubMed: 12379958]

77. Osol G, Moore LG. Maternal uterine vascular remodeling during pregnancy. Microcirculation. 2014; 21:38-47. [PubMed: 23941526]

78. Burton GJ, Watson AL, Hempstock J, Skepper JN, Jauniaux E. Uterine glands provide histiotrophic nutrition for the human fetus during the first trimester of pregnancy. J. Clin. Endocrinol. Metab. 2002; 87:2954-2959. [PubMed: 12050279]

79. Burton GJ, Hempstock J, Jauniaux E. Nutrition of the human fetus during the first trimester-a review. Placenta. 2001; 22(Suppl. A):S70-S77. [PubMed: 11312634]

80. Jauniaux E, et al. Onset of maternal arterial blood flow and placental oxidative stress. A possible factor in human early pregnancy failure. Am. J. Pathol. 2000; 157:2111-2122. [PubMed: 11106583]

81. Genbacev O, Joslin R, Damsky CH, Polliotti BM, Fisher SJ. Hypoxia alters early gestation human cytotrophoblast differentiation/invasion in vitro and models the placental defects that occur in preeclampsia. J. Clin. Invest. 1996; 97:540-550. [PubMed: 8567979]

82. Caniggia I, et al. Hypoxia-inducible factor- 1 mediates the biological effects of oxygen on human trophoblast differentiation through TGF $\beta(3)$. J. Clin. Invest. 2000; 105:577-587. [PubMed: 10712429]

83. Rajakumar A, Brandon HM, Daftary A, Ness R, Conrad KP. Evidence for the functional activity of hypoxia-inducible transcription factors overexpressed in preeclamptic placentae. Placenta. 2004; 25:763-769. [PubMed: 15451190]

84. Tal R, et al. Effects of hypoxia-inducible factor-1a overexpression in pregnant mice: possible implications for preeclampsia and intrauterine growth restriction. Am. J. Pathol. 2010; 177:2950 2962. [PubMed: 20952590]

85. Kanasaki K, et al. Deficiency in catechol-O-methyltransferase and 2-methoxyoestradiol is associated with pre-eclampsia. Nature. 2008; 453:1117-1121. [PubMed: 18469803]

86. Palmer K, et al. Severe early-onset preeclampsia is not associated with a change in placental catechol O-methyltransferase (COMT) expression. Am. J. Pathol. 2011; 178:2484-2488. [PubMed: 21531374]

87. Seol HJ, Cho GJ, Oh MJ, Kim HJ. 2-methoxyoestradiol levels and placental catechol-Omethyltransferase expression in patients with late-onset preeclampsia. Arch. Gynecol. Obstet. 2013; 287:881-886. [PubMed: 23233290]

88. Redman CW, Sargent IL. Placental stress and pre-eclampsia: a revised view. Placenta. 2009; 30(Suppl. A):S38-S42. [PubMed: 19138798]

89. Brosens JJ, Parker MG, McIndoe A, Pijnenborg R, Brosens IA. A role for menstruation in preconditioning the uterus for successful pregnancy. Am. J. Obstet. Gynecol. 2009; 200:615.e1615.e6. [PubMed: 19136085]

90. Moffett A, Hiby SE. How does the maternal immune system contribute to the development of preeclampsia? Placenta. 2007; 28(Suppl. A):S51-S56. [PubMed: 17292469]

91. Zhang K, Kaufman RJ. From endoplasmic-reticulum stress to the inflammatory response. Nature. 2008; 454:455-462. [PubMed: 18650916] 
92. Burton GJ, Yung HW, Cindrova-Davies T, Charnock-Jones DS. Placental endoplasmic reticulum stress and oxidative stress in the pathophysiology of unexplained intrauterine growth restriction and early onset preeclampsia. Placenta. 2009; 30(Suppl. A):S43-S48. [PubMed: 19081132]

93. Huppertz B, Kadyrov M, Kingdom JC. Apoptosis and its role in the trophoblast. Am. J. Obstet. Gynecol. 2006; 195:29-39. [PubMed: 16579915]

94. Redman CW, Sargent IL. Microparticles and immunomodulation in pregnancy and pre-eclampsia. J. Reprod. Immunol. 2007; 76:61-67. [PubMed: 17482271]

95. Lian IA, et al. Increased endoplasmic reticulum stress in decidual tissue from pregnancies complicated by fetal growth restriction with and without pre-eclampsia. Placenta. 2011; 32:823829. [PubMed: 21907405]

96. Burton GJ, Jauniaux E. Oxidative stress. Best Pract Res. Clin. Obstet. Gynaecol. 2011; 25:287299.

97. Cindrova-Davies T, Spasic-Boskovic O, Jauniaux E, Charnock-Jones DS, Burton GJ. Nuclear factor- $\kappa \mathrm{B}, \mathrm{p} 38$, and stress-activated protein kinase mitogen-activated protein kinase signaling pathways regulate proinflammatory cytokines and apoptosis in human placental explants in response to oxidative stress: effects of antioxidant vitamins. Am. J. Pathol. 2007; 170:1511-1520. [PubMed: 17456758]

98. Martin CB Jr, McGaughey HS Jr, Kaiser IH, Donner MW, Ramsey EM. Intermittent functioning of the uteroplacental arteries. Am. J. Obstet. Gynecol. 1964; 90:819-823. [PubMed: 14233674]

99. Burton GJ, Woods AW, Jauniaux E, Kingdom JC. Rheological and physiological consequences of conversion of the maternal spiral arteries for uteroplacental blood flow during human pregnancy. Placenta. 2009; 30:473-482. [PubMed: 19375795]

100. Many A, Hubel CA, Fisher SJ, Roberts JM, Zhou Y. Invasive cytotrophoblasts manifest evidence of oxidative stress in preeclampsia. Am. J. Pathol. 2000; 156:321-331. [PubMed: 10623681]

101. Vaughan JE, Walsh SW. Oxidative stress reproduces placental abnormalities of preeclampsia. Hypertens. Pregnancy. 2002; 21:205-223. [PubMed: 12517328]

102. George EM, Granger JP. Heme oxygenase in pregnancy and preeclampsia. Curr. Opin. Nephrol. Hypertens. 2013; 22:156-162. [PubMed: 23328500]

103. Zhao H, Wong RJ, Kalish FS, Nayak NR, Stevenson DK. Effect of heme oxygenase-1 deficiency on placental development. Placenta. 2009; 30:861-868. [PubMed: 19699520]

104. Nakamura M, et al. Cellular mRNA expressions of anti-oxidant factors in the blood of preeclamptic women. Prenat Diagn. 2009; 29:691-696. [PubMed: 19399816]

105. Lash GE, et al. Relationship between tissue damage and heme oxygenase expression in chorionic villi of term human placenta. Am. J. Physiol. Heart Circ. Physiol. 2003; 284:H160-H167. [PubMed: 12388278]

106. Farina A, et al. Gene expression in chorionic villous samples at 11 weeks' gestation from women destined to develop preeclampsia. Prenat. Diagn. 2008; 28:956-961. [PubMed: 18792924]

107. George EM, et al. Induction of heme oxygenase 1 attenuates placental ischemia-induced hypertension. Hypertension. 2011; 57:941-948. [PubMed: 21383306]

108. Costantine MM, et al. Using pravastatin to improve the vascular reactivity in a mouse model of soluble fms-like tyrosine kinase-1-induced preeclampsia. Obstet. Gynecol. 2010; 116:114-120. [PubMed: 20567176]

109. Gant NF, Chand S, Whalley PJ, MacDonald PC. The nature of pressor responsiveness to angiotensin II in human pregnancy. Obstet. Gynecol. 1974; 43:854. [PubMed: 4364211]

110. Dechend, R., Luft, FC., Lindheimer, M. Chesley's Hypertensive Disorders in Pregnancy. Lindheimer, MD.Roberts, JM., Cunningham, GC., editors. Elsevier; 2009. p. 287-296.

111. Wallukat G, et al. Patients with preeclampsia develop agonistic autoantibodies against the angiotensin AT1 receptor. J. Clin. Invest. 1999; 103:945-952. [PubMed: 10194466]

112. Dechend R, et al. Agonistic autoantibodies to the AT1 receptor in a transgenic rat model of preeclampsia. Hypertension. 2005; 45:742-746. [PubMed: 15699466]

113. Zhou CC, et al. Angiotensin receptor agonistic autoantibodies induce pre-eclampsia in pregnant mice. Nat. Med. 2008; 14:855-862. [PubMed: 18660815] 
114. Parrish MR, et al. The effect of immune factors, tumor necrosis factor-alpha, and agonistic autoantibodies to the angiotensin II type I receptor on soluble fms-like tyrosine- 1 and soluble endoglin production in response to hypertension during pregnancy. Am. J. Hypertens. 2010; 23:911-916. [PubMed: 20431529]

115. Xia Y, Kellems RE. Angiotensin receptor agonistic autoantibodies and hypertension: preeclampsia and beyond. Circ. Res. 2013; 113:78-87. [PubMed: 23788505]

116. Li J, LaMarca B, Reckelhoff JF. A model of preeclampsia in rats: the reduced uterine perfusion pressure (RUPP) model. Am. J. Physiol. Heart Circ. Physiol. 2012; 303:H1-H8. [PubMed: 22523250]

117. Dhillion P, et al. IL-17-mediated oxidative stress is an important stimulator of AT1-AA and hypertension during pregnancy. Am. J. Physiol. Regul. Integr Comp. Physiol. 2012; 303:R353R358. [PubMed: 22718806]

118. Girardi G, Yarilin D, Thurman JM, Holers VM, Salmon JE. Complement activation induces dysregulation of angiogenic factors and causes fetal rejection and growth restriction. J. Exp. Med. 2006; 203:2165-2175. [PubMed: 16923853]

119. Herse F, LaMarca B. Angiotensin II type 1 receptor autoantibody (AT1-AA)-mediated pregnancy hypertension. Am. J. Reprod. Immunol. 2013; 69:413-418. [PubMed: 23279165]

120. Novotny SR, et al. Activating autoantibodies to the angiotensin II type I receptor play an important role in mediating hypertension in response to adoptive transfer of CD4+ T lymphocytes from placental ischemic rats. Am. J. Physiol. Regul. Integr Comp. Physiol. 2012; 302:R1197-1201. [PubMed: 22461177]

121. Herse F, et al. Prevalence of agonistic autoantibodies against the angiotensin II type 1 receptor and soluble fms-like tyrosine kinase 1 in a gestational age-matched case study. Hypertension. 2009; 53:393-398. [PubMed: 19064815]

122. Stepan H, Wallukat G, Schultheiss HP, Faber R, Walther T. Is parvovirus B19 the cause for autoimmunity against the angiotensin II type receptor? J. Reprod. Immunol. 2007; 73:130-134. [PubMed: 17150255]

123. Naccasha N, et al. Phenotypic and metabolic characteristics of monocytes and granulocytes in normal pregnancy and maternal infection. Am. J. Obstet. Gynecol. 2001; 185:1118-1123. [PubMed: 11717644]

124. Lau SY, et al. Tumor necrosis factor-a, interleukin-6, and interleukin-10 levels are altered in preeclampsia: a systematic review and meta-analysis. Am. J. Reprod. Immunol. 2013; 70:412427. [PubMed: 23790133]

125. McCarthy FP, Kingdom JC, Kenny LC, Walsh SK. Animal models of preeclampsia: uses and limitations. Placenta. 2011; 32:413-419. [PubMed: 21497901]

126. Gervasi MT, et al. Phenotypic and metabolic characteristics of maternal monocytes and granulocytes in preterm labor with intact membranes. Am. J. Obstet. Gynecol. 2001; 185:11241129. [PubMed: 11717645]

127. Gervasi MT, et al. Maternal intravascular inflammation in preterm premature rupture of membranes. J. Matern. Fetal Neonatal Med. 2002; 11:171-175. [PubMed: 12380672]

128. Sabatier F, et al. Neutrophil activation in preeclampsia and isolated intrauterine growth restriction. Am. J. Obstet. Gynecol. 2000; 183:1558-1563. [PubMed: 11120528]

129. Ogge G, et al. Leukocytes of pregnant women with small-for-gestational age neonates have a different phenotypic and metabolic activity from those of women with preeclampsia. J. Matern. Fetal Neonatal Med. 2010; 23:476-487. [PubMed: 19916874]

130. Roberts JM, et al. Preeclampsia: an endothelial cell disorder. Am. J. Obstet. Gynecol. 1989; 161:1200-1204. [PubMed: 2589440]

131. Chaiworapongsa T, et al. Soluble adhesion molecule profile in normal pregnancy and preeclampsia. J. Matern. Fetal Neonatal Med. 2002; 12:19-27. [PubMed: 12422905]

132. Bretelle F, et al. Maternal endothelial soluble cell adhesion molecules with isolated small for gestational age fetuses: comparison with pre-eclampsia. BJOG. 2001; 108:1277-1282. [PubMed: 11843391]

133. Bussolino F, Benedetto C, Massobrio M, Camussi G. Maternal vascular prostacyclin activity in pre-eclampsia. Lancet. 1980; 2:702. [PubMed: 6106815] 
134. Walsh SW. Preeclampsia: an imbalance in placental prostacyclin and thromboxane production. Am. J. Obstet. Gynecol. 1985; 152:335-340. [PubMed: 3923838]

135. Freedman JE, et al. Deficient platelet-derived nitric oxide and enhanced hemostasis in mice lacking the NOSIII gene. Circ. Res. 1999; 84:1416-1421. [PubMed: 10381894]

136. Yallampalli $\mathrm{C}$, Garfield RE. Inhibition of nitric oxide synthesis in rats during pregnancy produces signs similar to those of preeclampsia. Am. J. Obstet. Gynecol. 1993; 169:1316-1320. [PubMed: 8238200]

137. Cadroy Y, et al. Evaluation of six markers of haemostatic system in normal pregnancy and pregnancy complicated by hypertension or pre-eclampsia. Br. J. Obstet. Gynaecol. 1993; 100:416-420. [PubMed: 8518239]

138. Chaiworapongsa T, et al. Evidence of in vivo generation of thrombin in patients with small-forgestational-age fetuses and pre-eclampsia. J. Matern. Fetal Neonatal Med. 2002; 11:362-367. [PubMed: 12389649]

139. Kobayashi T, Tokunaga N, Sugimura M, Kanayama N, Terao T. Predictive values of coagulation/ fibrinolysis parameters for the termination of pregnancy complicated by severe preeclampsia. Semin. Thromb. Hemost. 2001; 27:137-141. [PubMed: 11372767]

140. Sharma SK, Philip J, Whitten CW, Padakandla UB, Landers DF. Assessment of changes in coagulation in parturients with preeclampsia using thromboelastography. Anesthesiology. 1999; 90:385-390. [PubMed: 9952141]

141. Fakhouri F, Vercel C, Fremeaux-Bacchi V. Obstetric nephrology: AKI and thrombotic microangiopathies in pregnancy. Clin. J.. Am. Soc. Nephrol. 2012; 7:2100-2106. [PubMed: 22879435]

142. Ferrara N, et al. Heterozygous embryonic lethality induced by targeted inactivation of the VEGF gene. Nature. 1996; 380:439-442. [PubMed: 8602242]

143. Torry DS, Wang HS, Wang TH, Caudle MR, Torry RJ. Preeclampsia is associated with reduced serum levels of placenta growth factor. Am. J. Obstet. Gynecol. 1998; 179:1539-1544. [PubMed: 9855593]

144. Maynard SE, et al. Excess placental soluble fms-like tyrosine kinase 1 (sFlt1) may contribute to endothelial dysfunction, hypertension, and proteinuria in preeclampsia. J. Clin. Invest. 2003; 111:649-658. [PubMed: 12618519]

145. Yang JC, et al. A randomized trial of bevacizumab, an anti-vascular endothelial growth factor antibody, for metastatic renal cancer. N. Engl. J. Med. 2003; 349:427-434. [PubMed: 12890841]

146. Levine RJ, et al. Circulating angiogenic factors and the risk of preeclampsia. N. Engl. J. Med. 2004; 350:672-683. [PubMed: 14764923]

147. Chaiworapongsa T, et al. Evidence supporting a role for blockade of the vascular endothelial growth factor system in the pathophysiology of preeclampsia. Young Investigator Award. Am. J. Obstet. Gynecol. 2004; 190:1541-1550. [PubMed: 15284729]

148. Chaiworapongsa T, et al. Plasma soluble vascular endothelial growth factor receptor-1 concentration is elevated prior to the clinical diagnosis of pre-eclampsia. J. Matern. Fetal Neonatal Med. 2005; 17:3-18. [PubMed: 15804781]

149. Widmer M, et al. Mapping the theories of preeclampsia and the role of angiogenic factors: a systematic review. Obstet. Gynecol. 2007; 109:168-180. [PubMed: 17197602]

150. Romero R, et al. A longitudinal study of angiogenic (placental growth factor) and anti-angiogenic (soluble endoglin and soluble vascular endothelial growth factor receptor-1) factors in normal pregnancy and patients destined to develop preeclampsia and deliver a small for gestational age neonate. J. Matern. Fetal Neonatal Med. 2008; 21:9-23. [PubMed: 18175241]

151. Bujold E, et al. Evidence supporting that the excess of the sVEGFR-1 concentration in maternal plasma in preeclampsia has a uterine origin. J. Matern. Fetal Neonatal Med. 2005; 18:9-16. [PubMed: 16105786]

152. Maynard SE, et al. Gestational angiogenic biomarker patterns in high risk preeclampsia groups. Am. J. Obstet. Gynecol. 2013; 53:e1-e9.

153. Wolf M, et al. Circulating levels of the antiangiogenic marker sFLT-1 are increased in first versus second pregnancies. Am. J. Obstet. Gynecol. 2005; 193:16-22. [PubMed: 16021053] 
154. Bdolah Y, et al. Twin pregnancy and the risk of preeclampsia: bigger placenta or relative ischemia? Am. J. Obstet. Gynecol. 2008; 198:428.e1-428.e6. [PubMed: 18191808]

155. Cohen A, et al. Circulating levels of the antiangiogenic marker soluble FMS-like tyrosine kinase 1 are elevated in women with pregestational diabetes and preeclampsia: angiogenic markers in preeclampsia and preexisting diabetes. Diabetes Care. 2007; 30:375-377. [PubMed: 17259514]

156. Levine RJ, et al. Soluble endoglin and other circulating antiangiogenic factors in preeclampsia. N. Engl. J. Med. 2006; 355:992-1005. [PubMed: 16957146]

157. Rajakumar A, et al. Extra-placental expression of vascular endothelial growth factor receptor-1, (Flt-1) and soluble Flt-1 (sFlt-1), by peripheral blood mononuclear cells (PBMCs) in normotensive and preeclamptic pregnant women. Placenta. 2005; 26:563-573. [PubMed: 15993706]

158. Rajakumar A, et al. Novel soluble Flt-1 isoforms in plasma and cultured placental explants from normotensive pregnant and preeclamptic women. Placenta. 2009; 30:25-34. [PubMed: 19010535]

159. Sela S, et al. A novel human-specific soluble vascular endothelial growth factor receptor 1: celltype-specific splicing and implications to vascular endothelial growth factor homeostasis and preeclampsia. Circ. Res. 2008; 102:1566-1574. [PubMed: 18515749]

160. Gilbert JS, Babcock SA, Granger JP. Hypertension produced by reduced uterine perfusion in pregnant rats is associated with increased soluble fms-like tyrosine kinase-1 expression. Hypertension. 2007; 50:1142-1147. [PubMed: 17923588]

161. Makris A, et al. Uteroplacental ischemia results in proteinuric hypertension and elevated sFLT-1. Kidney Int. 2007; 71:977-984. [PubMed: 17377512]

162. Rajakumar A, et al. Transcriptionally active syncytial aggregates in the maternal circulation may contribute to circulating soluble fms-like tyrosine kinase 1 in preeclampsia. Hypertension. 2012; 59:256-264. [PubMed: 22215706]

163. Lockwood CJ, et al. Thrombin regulates soluble fms-like tyrosine kinase-1 (sFlt-1) expression in first trimester decidua: implications for preeclampsia. Am. J. Pathol. 2007; 170:1398-1405. [PubMed: 17392178]

164. Nagamatsu T, et al. Cytotrophoblasts up-regulate soluble fms-like tyrosine kinase-1 expression under reduced oxygen: an implication for the placental vascular development and the pathophysiology of preeclampsia. Endocrinology. 2004; 145:4838-4845. [PubMed: 15284201]

165. Kendall RL, Thomas KA. Inhibition of vascular endothelial cell growth factor activity by an endogenously encoded soluble receptor. Proc. Natl Acad. Sci. USA. 1993; 90:10705-10709. [PubMed: 8248162]

166. Esser S, et al. Vascular endothelial growth factor induces endothelial fenestrations in vitro. J. Cell Biol. 1998; 140:947-959. [PubMed: 9472045]

167. Sandrim VC, et al. Nitric oxide formation is inversely related to serum levels of antiangiogenic factors soluble fms-like tyrosine kinase- 1 and soluble endogline in preeclampsia. Hypertension. 2008; 52:402-407. [PubMed: 18574068]

168. Cindrova-Davies T, Sanders DA, Burton GJ, Charnock-Jones DS. Soluble FLT1 sensitizes endothelial cells to inflammatory cytokines by antagonizing VEGF receptor-mediated signalling. Cardiovasc. Res. 2011; 89:671-679. [PubMed: 21139021]

169. Eremina V, et al. Glomerular-specific alterations of VEGF-A expression lead to distinct congenital and acquired renal diseases. J. Clin. Invest. 2003; 111:707-716. [PubMed: 12618525]

170. Craici IM, et al. Podocyturia predates proteinuria and clinical features of preeclampsia: longitudinal prospective study. Hypertension. 2013; 61:1289-1296. [PubMed: 23529165]

171. Chen G, et al. Effects of angiogenic factors, antagonists, and podocyte injury on development of proteinuria in preeclampsia. Reprod. Sci. 2013; 20:579-588. [PubMed: 22991381]

172. Venkatesha $S$, et al. Soluble endoglin contributes to the pathogenesis of preeclampsia. Nat. Med. 2006; 12:642-649. [PubMed: 16751767]

173. McAllister KA, et al. Endoglin, a TGF- $\beta$ binding protein of endothelial cells, is the gene for hereditary haemorrhagic telangiectasia type 1. Nat. Genet. 1994; 8:345-351. [PubMed: 7894484]

174. Li DY, et al. Defective angiogenesis in mice lacking endoglin. Science. 1999; 284:1534-1537. [PubMed: 10348742] 
175. Reimer T, et al. Angiogenic factors and acute-phase proteins in serum samples of preeclampsia and HELLP patients: a matched-pair analysis. J. Matern. Fetal Neonatal Med. 2013; 26:263-269. [PubMed: 23020582]

176. Young B, et al. The use of angiogenic biomarkers to differentiate non-HELLP related thrombocytopenia from HELLP syndrome. J. Matern. Fetal Neonatal Med. 2010; 23:366-370. [PubMed: 19701867]

177. Chaiworapongsa T, et al. The maternal plasma soluble vascular endothelial growth factor receptor-1 concentration is elevated in SGA and the magnitude of the increase relates to Doppler abnormalities in the maternal and fetal circulation. J. Matern. Fetal Neonatal Med. 2008; 21:2540. [PubMed: 18175242]

178. Chaiworapongsa T, et al. A subset of patients destined to develop spontaneous preterm labor has an abnormal angiogenic/anti-angiogenic profile in maternal plasma: evidence in support of pathophysiologic heterogeneity of preterm labor derived from a longitudinal study. J. Matern. Fetal Neonatal Med. 2009; 22:1122-1139. [PubMed: 19916710]

179. Romero R, et al. An imbalance between angiogenic and anti-angiogenic factors precedes fetal death in a subset of patients: results of a longitudinal study. J. Matern. Fetal Neonatal Med. 2010; 23:1384-1399. [PubMed: 20459337]

180. Chaiworapongsa T, et al. Maternal plasma concentrations of angiogenic/antiangiogenic factors in the third trimester of pregnancy to identify the patient at risk for stillbirth at or near term and severe late preeclampsia. Am. J. Obstet. Gynecol. 2013; 208:287.e1-287.e15. [PubMed: 23333542]

181. Whitten AE, et al. Evidence of an imbalance of angiogenic/antiangiogenic factors in massive perivillous fibrin deposition (maternal floor infarction): a placental lesion associated with recurrent miscarriage and fetal death. Am. J. Obstet. Gynecol. 2013; 208:310.e1-310.e11. [PubMed: 23333548]

182. Muttukrishna S, et al. Soluble Flt-1 and PIGF: new markers of early pregnancy loss? PLoS ONE. 2011; 6:pe18041.

183. Signore C, et al. Circulating angiogenic factors and placental abruption. Obstet. Gynecol. 2006; 108:338-344. [PubMed: 16880304]

184. Koga K, et al. Elevated serum soluble fms-like tyrosine kinase 1 (sFlt1) level in women with hydatidiform mole. Fertil. Steril. 2010; 94:305-308. [PubMed: 19269632]

185. Bdolah Y, et al. Circulating angiogenic proteins in trisomy 13. Am. J. Obstet. Gynecol. 2006; 194:239-245. [PubMed: 16389038]

186. Kusanovic JP, et al. Twin-to-twin transfusion syndrome: an antiangiogenic state? Am. J. Obstet. Gynecol. 2008; 198:382.e1-382.e8. [PubMed: 18395032]

187. Romero R. The child is the father of the man. Prenat. Neonat. Med. 1996; 1:8-11.

188. Romero R. Prenatal medicine: the child is the father of the man. 1996. J. Matern. Fetal Neonatal Med. 2009; 22:636-639. [PubMed: 19736614]

189. Fraser SH, Tudehope DI. Neonatal neutropenia and thrombocytopenia following maternal hypertension. J. Paediatr. Child Health. 1996; 32:31-34. [PubMed: 8652209]

190. Sarhanis P, Pugh DH. Resolution of pre-eclampsia following intrauterine death of one twin. Br. J. Obstet. Gynaecol. 1992; 99:159-160. [PubMed: 1554671]

191. Conde-Agudelo A, Villar J, Lindheimer M. Maternal infection and risk of preeclampsia: systematic review and metaanalysis. Am. J. Obstet. Gynecol. 2008; 198:7-22. [PubMed: 18166297]

192. Leveno, KJ., Cunningham, FG. Chesley's Hypertensive Disorders in Pregnancy. Lindheimer, MD.Roberts, JM., Cunningham, GC., editors. Elsevier; 2009. p. 389-414.

193. Saftlas AF, Olson DR, Franks AL, Atrash HK, Pokras R. Epidemiology of preeclampsia and eclampsia in the United States, 1979-1986. Am. J. Obstet. Gynecol. 1990; 163:460-465. [PubMed: 2386132]

194. Zhang J, Zeisler J, Hatch MC, Berkowitz G. Epidemiology of pregnancy-induced hypertension. Epidemiol. Rev. 1997; 19:218-232. [PubMed: 9494784]

195. Eskenazi B, Fenster L, Sidney S. A multivariate analysis of risk factors for preeclampsia. JAMA. 1991; 266:237-241. [PubMed: 2056625] 
196. Bodnar LM, Ness RB, Markovic N, Roberts JM. The risk of preeclampsia rises with increasing prepregnancy body mass index. Ann. Epidemiol. 2005; 15:475-482. [PubMed: 16029839]

197. Branch DW, Silver RM, Blackwell JL, Reading JC, Scott JR. Outcome of treated pregnancies in women with antiphospholipid syndrome: an update of the Utah experience. Obstet. Gynecol. 1992; 80:614-620. [PubMed: 1407882]

198. Lima F, et al. A study of sixty pregnancies in patients with the antiphospholipid syndrome. Clin. Exp. Rheumatol. 1996; 14:131-136. [PubMed: 8737718]

199. Lie RT, et al. Fetal and maternal contributions to risk of pre-eclampsia: population based study. BMJ. 1998; 316:1343-1347. [PubMed: 9563982]

200. Schieve LA, Handler A, Hershow R, Persky V, Davis F. Urinary tract infection during pregnancy: its association with maternal morbidity and perinatal outcome. Am. J. Public Health. 1994; 84:405-410. [PubMed: 8129056]

201. Lisonkova S, Joseph KS. Incidence of preeclampsia: risk factors and outcomes associated with early-versus late-onset disease. Am. J. Obstet. Gynecol. 2013; 209:544.e541-544.e512. [PubMed: 23973398] 


\section{Box 1}

\section{Risk factors for pre-eclampsia ${ }^{192}$}

- $\quad$ Nulliparous women

- Extreme maternal age $\left(<20\right.$ years ${ }^{193}$ or $>35$ years $\left.{ }^{194}\right)$

- $\quad$ History of pre-eclampsia in previous pregnancy

- Multi-fetal gestation

- $\quad$ Obesity 195,196

- $\quad$ Family history of pre-eclampsia (mother or sister)

- $\quad$ Pre-existing medical conditions, including chronic hypertension, diabetes mellitus, antiphospholipid syndrome, ${ }^{197,198}$ thrombophilia, autoimmune disease, renal disease, infertility

- $\quad$ Limited sperm exposure

- 'Dangerous father'28,199

- Urinary tract infection 191,200 


\section{Box 2}

\section{Classification of hypertensive disorders of pregnancy}

\section{Chronic hypertension}

- $\quad$ Blood pressure $\geq 140 / 90 \mathrm{mmHg}$ before pregnancy and at $<20$ weeks of gestation, or diagnosed for the first time during pregnancy and does not resolve postpartum

\section{Pre-eclampsia and eclampsia}

- $\quad$ Blood pressure $\geq 140 / 90 \mathrm{mmHg}$ on two occasions at least $4 \mathrm{~h}$ apart or $\geq 160 / 110 \mathrm{mmHg}$ within a shorter interval (minutes), at $\geq 20$ weeks of gestation, in women with previously normal blood pressure and proteinuria*

- In the absence of proteinuria, new-onset hypertension plus new onset of any of the following features: serum creatinine concentrations $>97 \mu \mathrm{mol} / \mathrm{l}$ or doubling of serum creatinine concentration in the absence of other renal disease; elevation of liver transaminases to twice normal concentration; pulmonary oedema; and cerebral or visual symptoms

- $\quad$ Eclampsia: seizures in women with pre-eclampsia that cannot be attributed to other causes

\section{Pre-eclampsia superimposed on chronic hypertension}

- Women with hypertension (at $<20$ weeks gestation) and new-onset proteinuria*

- In women with hypertension and proteinuria* (at $<20$ weeks gestation), development of any of the following features: sudden increase in proteinuria;** sudden increase in blood pressure in women whose hypertension was previously well controlled; thrombocytopenia (platelet count $<100,000$ per $\mathrm{mm}^{3}$ ); and elevated liver transaminase levels

\section{Gestational hypertension}

- $\quad$ New-onset blood pressure $\geq 140 / 90 \mathrm{mmHg}$ detected at $\geq 20$ weeks gestation without proteinuria

- $\quad$ Pre-eclampsia does not develop and blood pressure returns to normal by 12 weeks postpartum

*Defined as urinary protein excretion $\geq 300 \mathrm{mg} / 24 \mathrm{~h}$, a total protein:creatinine ratio $\geq 30$ $\mathrm{mg} / \mathrm{mmol}$ (or $\searrow 0.3$ when both are measured in $\mathrm{mg} / \mathrm{dl}$ ) or a dipstick reading of $\geq 1+$ (only if other quantitative methods are not available). ${ }^{7}$ 


\section{Box 3}

\section{Classification of pre-eclampsias}

Early pre-eclampsia ( $<34$ weeks*)

- Uncommon (prevalence $0.38 \%$ or $12 \%$ of all pre-eclampsia) ${ }^{201}$

- Associated with extensive villous and vascular lesions of the placenta

- Higher risk of maternal and fetal complications than late pre-eclampsia

\section{Late pre-eclampsia ( $\geq 34$ weeks*)}

- Majority of all cases of pre-eclampsia (prevalence $2.72 \%$ or $88 \%$ of all preeclampsia) $)^{201}$

- $\quad$ Minimal placental lesions

- Maternal factors (such as metabolic syndrome and hypertension) have important roles

- Most cases of eclampsia and maternal death occur in late disease

*Gestational age at diagnosis or delivery. 3,44 


\section{Box 4}

\section{Severe features of pre-eclampsia (one or more of these findings)}

- $\quad$ Systolic blood pressure $\geq 160 \mathrm{mmHg}$, or diastolic blood pressure $\geq 110 \mathrm{mmHg}$ on two occasions at $\geq 4 \mathrm{~h}$ apart while the patient is on bed rest

- $\quad$ Platelet count $<100,000$ per mm3

- $\quad$ Elevated liver enzymes (twice normal concentrations)

- Renal insufficiency (serum creatinine concentration $>1.1 \mathrm{mg} / \mathrm{dl}$ or a doubling of serum creatinine concentration) or oliguria ( $<500 \mathrm{ml}$ in $24 \mathrm{~h})$

- Pulmonary oedema or cyanosis

- $\quad$ New-onset cerebral or visual disturbances

- Severe persistent right upper quadrant or epigastric pain

Adapted from the Am. J. Obstet. Gynecol. 205, Sibai, B. M. Evaluation and management of severe preeclampsia before 34 weeks' gestation, 191-198 @ (2011), with permission from Elsevier. 


\section{Key points}

- Diagnosis of pre-eclampsia is based on new-onset hypertension and proteinuria at $\geq 20$ weeks of gestation or, in the absence of proteinuria, hypertension together with evidence of systemic disease.

- Genetic and environmental factors are thought to create conditions leading to defective deep placentation; the injured placenta then releases factors into the maternal circulation that induce pre-eclampsia.

- $\quad$ Pre-eclampsia is characterized by multiple aetiologies and pathogenetic mechanisms, a long subclinical phase, fetal involvement, adaptive clinical manifestations and gene-environment interactions.

- An imbalance between angiogenic and antiangiogenic factors has emerged as a central pathogenetic mechanism in pre-eclampsia.

- An antiangiogenic state can also be observed in conditions other than preeclampsia, including intrauterine growth restriction, fetal death, spontaneous preterm labour and maternal floor infarction.

- The severity and timing of the antiangiogenic state, as well as maternal susceptibility, might determine the clinical presentation of pre-eclampsia. 
a Hypertension

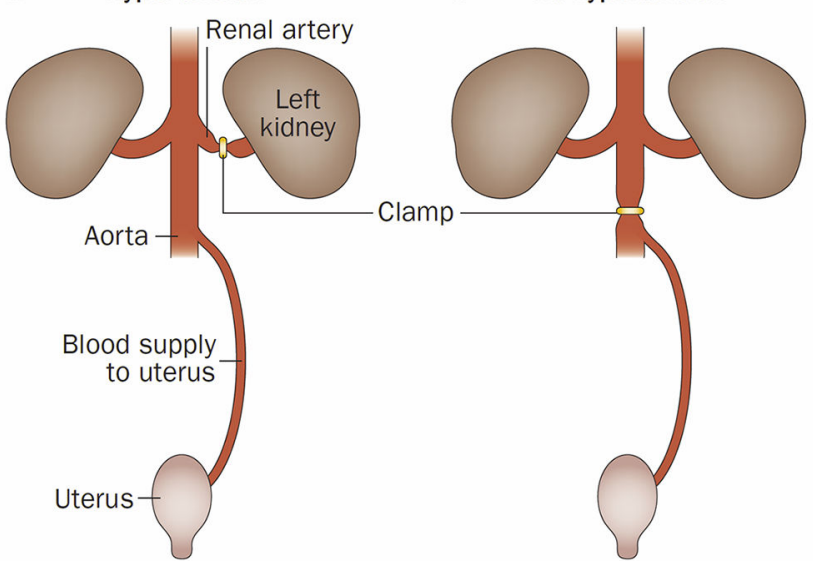

c Hypertension

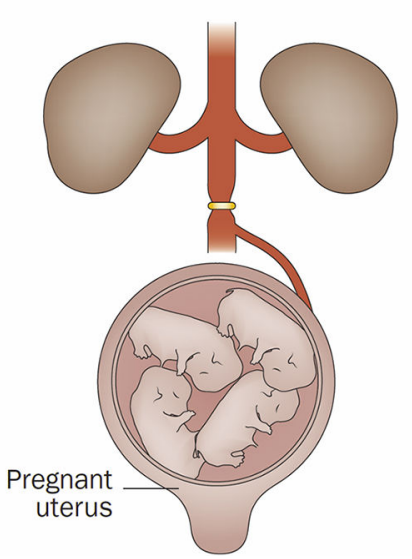

d No hypertension

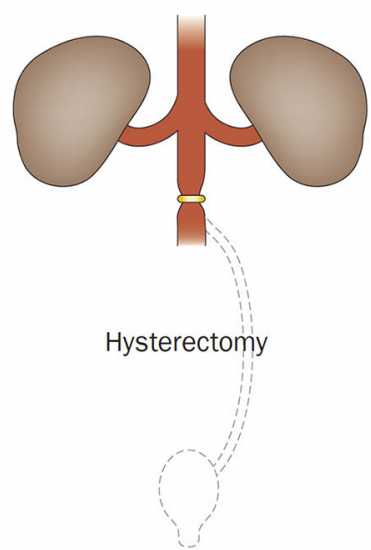

Figure 1. An experiment supporting the concept that hypertension in pregnancy represents a uteroplacental response to ischaemia

A. In the Goldblatt model of renovascular hypertension, clamping the renal artery leads to development of hypertension through renal ischaemia in nonpregnant animals. B. By contrast, clamping the aorta below the renal arteries does not induce hypertension in nonpregnant animals. C. Aortic clamping in pregnant animals leads to hypertension. D. After hysterectomy, however, hypertension can no longer be elicited by aortic clamping, suggesting that the ischaemic pregnant uterus is the source of signals that lead to maternal systemic hypertension. Permission obtained from Semin. Perinatol. 12, Romero, R. et al. Toxemia: new concepts in an old disease, 302-323 @ Elsevier (1988). 
Normal pregnancy

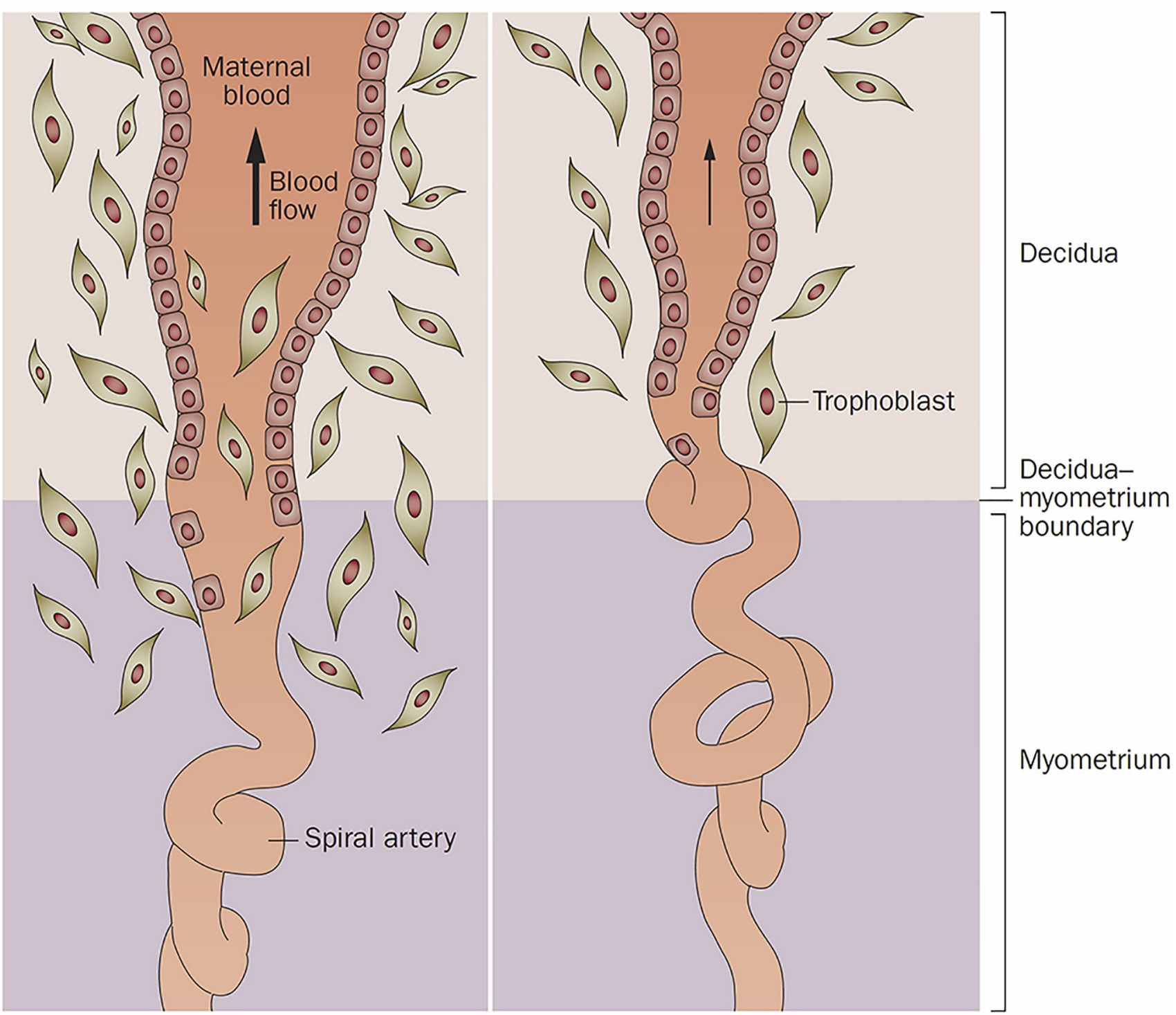

Figure 2. Failure of physiological transformation of the spiral arteries is implicated in preeclampsia

A. In a normal pregnancy, physiological transformation of the myometrial segment of the spiral artery occurs. Trophoblast cells extend to both the decidual segment and one-third of the myometrial segment of the spiral artery. Both the arterial media and endothelium are destroyed by trophoblasts, converting the arteries into wide-calibre vessels and increasing the delivery of blood to the intervillous space. B. In pregnancies affected by pre-eclampsia, a key feature associated with the failure of physiological transformation of the spiral arteries is lack of invasion of the trophoblasts into the myometrial segment of the spiral artery. The resulting lack of transformation of blood vessels results in narrow spiral arteries, a disturbed pattern of blood flow and reduced uteroplacental perfusion. Permission obtained from Nature Publishing Group ( $)$ Moffett-King, A. et al. Nat. Rev. Immunol. 2, 656-663 (2002). 


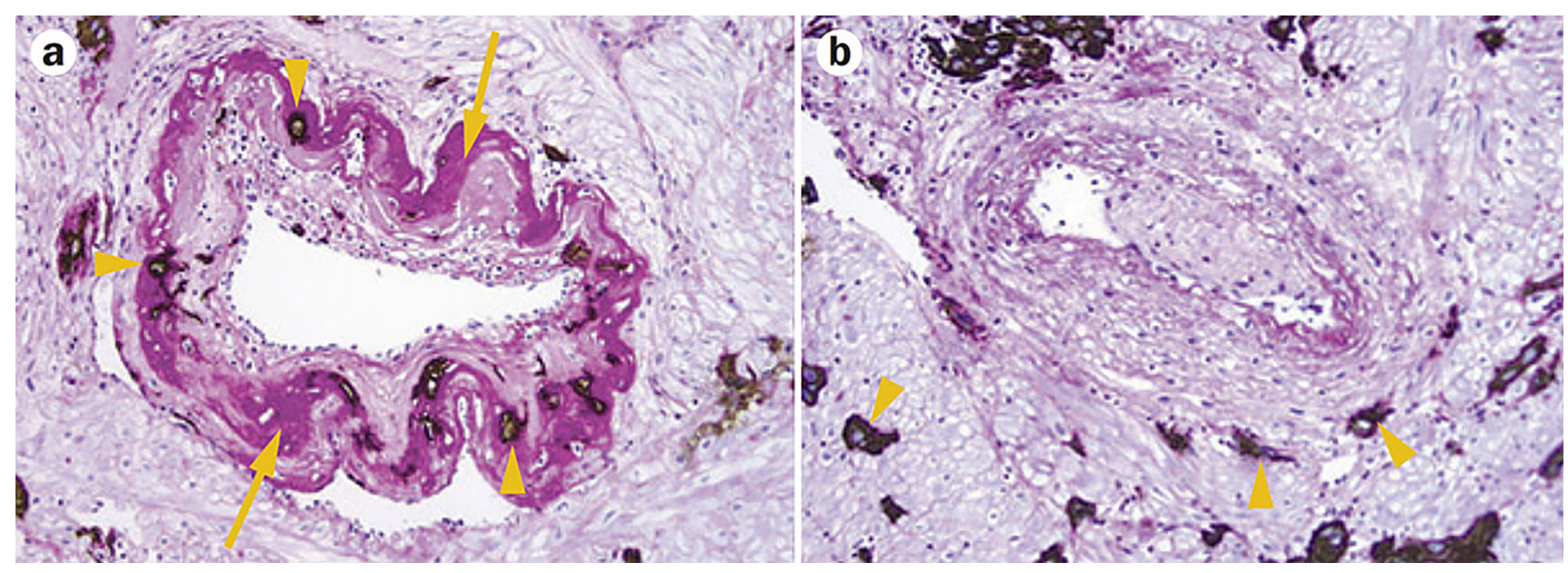

Figure 3. Transformed and nontransformed spiral arteries in the myometrium

A. Transformed spiral arteries are characterized by the presence of intramural trophoblasts (arrowheads) and fibrinoid degeneration (arrows) of the arterial wall. B. Nontransformed spiral arteries lack intramural trophoblasts and fibrinoid degeneration, and retain intact arterial contours. Arrowheads indicate the presence of trophoblasts in myometrium, but not in the wall of the spiral artery. Both images stained with cytokeratin 7 (brown) and periodic acid-Schiff (pink), magnification $\times 200$. Permission obtained from the NIH $@$ Espinoza, J. et al. J. Perinat. Med. 34, 447-458 (2006). 


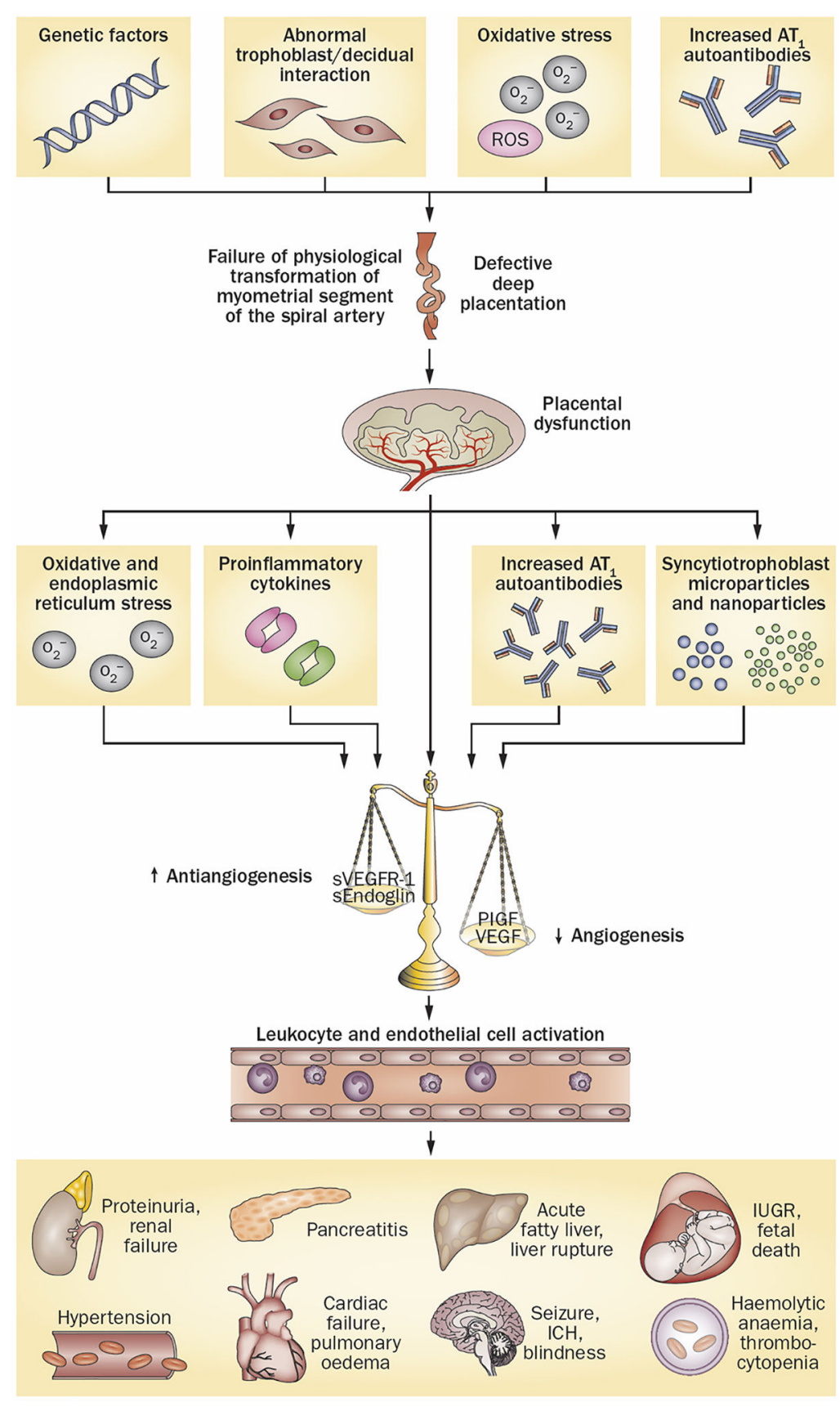

Figure 4. Integrated model of the complex pathophysiology of pre-eclampsia

Genetic (including maternal-fetal genotype incompatibility) and environmental (preconception exposure to paternal antigens) factors disrupt pregnancy-induced immunomodulation, leading to trophoblast and decidual pathology, shallow endometrial invasion and failure of physiological transformation of the spiral arteries (a disorder of deep placentation). The degree of uterine ischaemia is determined by the severity of the placentation defect and fetal demand on the blood supply. Obstetric disorders occur when these two factors are mismatched. The timing and extent of the mismatch determines the clinical presentation (fetal death, pre-eclampsia with IUGR, IUGR alone and late pre- 
eclampsia). Pre-eclampsia occurs as a result of adaptive responses involving the release of inflammatory cytokines, anti- $\mathrm{AT}_{1}$ autoantibodies, angiogenic and antiangiogenic factors and syncytiotrophoblast-derived particles into the maternal circulation. Collectively, these factors induce leukocyte activation, intravascular inflammation, endothelial cell dysfunction and excessive thrombin generation. The multiorgan features of pre-eclampsia result from the consequences of these processes in different target organs. Abbreviations: $\mathrm{AT}_{1}$, type-1 angiotensin II receptor; ER, endoplasmic reticulum; ICH, intracerebral haemorrhage; IUGR, intrauterine growth restriction; PIGF, placental growth factor; ROS, reactive oxygen species; s, soluble; VEGF, vascular endothelial growth factor; VEGFR-1, vascular endothelial growth factor receptor 1 . 